TEXTO PARA DISCUSSÃO

\begin{tabular}{|} 
No. 647 \\
What if Brazil Hadn't Floated the Real \\
in 1999? \\
Carlos Viana de Carvalho \\
André D. Vilela \\
\hline
\end{tabular}

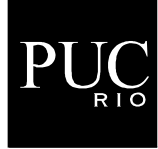

DEPARTAMENTO DE ECONOMIA www.econ.puc-rio.br 


\title{
What if Brazil Hadn't Floated the Real in 1999?*
}

\author{
Carlos Viana de Carvalho \\ PUC-Rio
}

\author{
André D. Vilela \\ Banco Central do Brasil
}

November, 2015

\begin{abstract}
We estimate a dynamic, stochastic, general equilibrium model of the Brazilian economy taking into account the transition from a currency peg to inflation targeting that took place in 1999. The estimated model exhibits quite different dynamics under the two monetary regimes. We use it to produce counterfactual histories of the transition from one regime to another, given the estimated history of structural shocks. Our results suggest that maintaining the currency peg would have been too costly, as interest rates would have had to remain at extremely high levels for several quarters, and GDP would have collapsed. Accelerating the pace of nominal exchange rate devaluations after the Asian Crisis would have lead to higher inflation and interest rates, and slightly lower GDP. Finally, the first half of 1998 arguably provided a window of opportunity for a smooth transition between monetary regimes.
\end{abstract}

JEL classification codes: E52, F41

Keywords: monetary policy, regime shift, currency peg, inflation targeting, Brazil

${ }^{*}$ This paper is based on Vilela (2014). For comments and suggestions, we thank Tiago Berriel, Diogo Guillén, and seminar participants at the Central Bank of Brazil, IPEA, and the Conference "DSGE models for Brazil: SAMBA and beyond", held at EESP in August 2014. The views expressed in this paper are those of the authors and do not necessarily reflect the position of the Central Bank of Brazil. E-mails: cvianac@econ.puc-rio.br, andre.vilela@bcb.gov.br. 


\section{Introduction}

"Reserves grew quickly and confidence returned. Maybe this is what made us miss the opportunity to review the exchange rate issue in the first months of 1998, when it might have been possible to do it." (Cardoso, 2006) $)^{1}$

The transition from an exchange rate crawling peg to the inflation targeting regime with floating exchange rates was the most significant monetary policy change in Brazil since the Plano Real in 1994. The change occurred during a troubled period, after a sequence of international crises, ${ }^{2}$ an agreement with the IMF, and presidential elections in October 1998. After a marked devaluation of the Real in January 1999, followed by an increase in inflation in the short run, the Central Bank of Brazil (CBB) increased interest rates to $45 \%$ p.a., in an attempt to keep inflation expectations from unanchoring. Subsequently, the CBB began to operate under the inflation targeting regime, made official in June, 1999.

Changes to the exchange rate peg, including the possibility of abandoning that regime, were the subject of unending debates while it lasted. Even the adoption of inflation targeting with floating exchange rates was not enough to put an end to that debate. Would it have been possible and desirable to keep the exchange rate pegged? What would have happened if the change in regime had occurred earlier? What would have been the most favorable moment for such change?

In this paper we answer some of these questions using a dynamic, stochastic, general equilibrium model ("DSGE") based on Galí and Monacelli (2005) and Justiniano and Preston (2010), estimated for the Brazilian economy. The model is estimated using macroeconomic data from the third quarter of 1995 to the second quarter of 2013. Following Cúrdia and Finocchiaro (2013), we explicitly model the change of monetary regime that took place in the first quarter of 1999 . To that end, we allow the coefficients of the interest rate rule followed by the CBB to vary across regimes. In particular, with the adoption of inflation targeting the $\mathrm{CBB}$ ceases to react to deviations of the nominal exchange rate from a pre-stablished parity, and starts to react to deviations of inflation from target. For the sake of simplicity, the change of regime comes as a surprise to economic agents. The other parameters of the model, related to preferences, technology etc., are assumed to be invariant.

We use the estimated model to recover the structural shocks that hit the Brazilian economy during the sample period, and simulate counterfactual histories. Specifically, we analyze the effects of alternative timings for the adoption of inflation targeting with floating exchange rates.

Before we summarize our main results, a few observations are in order. In any exercise of this kind,

\footnotetext{
${ }^{1}$ Originally in Portuguese: "Rapidamente as reservas cresceram e a confiança voltou. Talvez tenha sido isso que nos levou a perder oportunidades para rever a questão cambial no primeiro quadrimestre de 1998, quando eventualmente teria sido possível fazê-lo". Our own translation.

${ }^{2}$ Asian Crisis in 1997 and Russian Crisis in 1998.
} 
the results and conclusions must be seen as conditional on the details of the model, data and estimation method used. For our purposes, the caveats associated with the model are particularly important.

The estimated model may be suitable for studying aggregate fluctuations and questions related to macroeconomic stabilization policies. However, it is silent on any issue that pertains to the long run. This is so because there is no channel in the model through which policies may affect trend growth. Hence, the model should only be used to address questions that can be circumscribed to business cycle frequencies.

As in most of the literature, we work with an approximation of the model around a zero inflation steady state. However, during our sample period the Brazilian economy faced important shocks, including the monetary regime change itself. In future work, it would be interesting to review the points made in this paper using methods that preserve the non-linearity of the model. Additionally, it would be advisable to allow for trend inflation, so as to bring the steady state of the model closer to the data.

The hypothesis that the parameters of the economy other than those of the monetary policy rule are invariant ("structural") is inherent to the idea that the model is well specified and immune to the Lucas Critique. This hypothesis can be tested econometrically and, if rejected, the model specification can be changed. ${ }^{3}$ Similarly, we could consider a model with alternating monetary regimes, with transition probabilities that are understood by economic agents. This would allow us to incorporate expectations of changes in the exchange rate regime, which certainly existed to varying degrees before the adoption of a floating exchange rate in January $1999 .^{4}$

The questions that we find most relevant pertain to the viability of the monetary policies used in some of the counterfactual histories - notably the one that simulates the continuation of the exchange rate crawling peg regime. In the model, sticking to this regime is always a viable option. There are no political pressures, confidence crises, speculative attacks, nor loss of international reserves. ${ }^{5}$ In reality, one can argue that the defense of a currency peg is simply not viable in certain circumstances. Incorporating the role of limited foreign exchange reserves and speculative attacks in such a DSGE model is an interesting avenue for research, which, as far as we know, remains unexplored.

The discussion in the previous paragraph brings us to the most important caveat, which pertains to fiscal policy - something that the model essentially abstracts from. One may reasonably argue

\footnotetext{
${ }^{3}$ Another option would be to allow for changes in some "structural parameters". Despite the fact that this route seems to violate the spirit of the Lucas Critique, there is evidence that some parameters usually taken to be structural can vary over time in an important manner (e.g., Guiso et al. 2013). It is worth mentioning that this type of evidence is not in conflict with the essence of the Lucas Critique.

${ }^{4}$ These expectations can be explicitly modeled as in Davig and Leeper (2010), who introduce a Markov switching monetary policy rule in the basic new Keynesian model. However, for a first exercise approaching the questions in this paper - and taking into consideration that our analysis is based on quarterly data - the assumption of a surprise change in the monetary regime may be less problematic than it seems at first.

${ }^{5}$ The reader who is not familiar with the recent literature in Monetary Economics may find it surprising that the model assumes a cashless economy. In this respect, we follow the approach advocated by Woodford (2003), to which we refer the readers who wish to deepen their understanding of the topic.
} 
that the pressure to float the Real resulted largely from a perception that Brazil's fiscal policy was unsustainable. This would have imposed limits to monetary policy and rendered the defense of the currency peg impossible. This issue can be addressed in a model with relevant interactions between monetary and fiscal policies - possibly with regime shifts applicable to both of them. In that context, it would be natural to assume that the risk premium associated with foreign indebtedness depends on the country's fiscal position. As a result, the "structural shocks" recovered from the estimated model could change significantly, leading to important differences in some of the counterfactual histories that we construct (more on that latter).

With those caveats in mind, let us move to the results. As expected, the estimated parameters for the crawling peg regime indicate that monetary policy was geared towards the maintenance of the nominal exchange rate around the levels defined by the CBB. In turn, in the inflation targeting regime, the estimated parameters suggest that monetary policy focused on stabilizing inflation. ${ }^{6}$ In addition, the results suggest a more predictable and systematic behavior on the part of the CBB, reflected in the lower variance of monetary policy shocks and a higher degree of interest rate smoothing.

The estimated monetary policy rules lead to very different macroeconomic dynamics in response to structural disturbances - especially foreign shocks. In particular, the results suggest that the classic role of floating exchange rates - namely, buffering the effects of those shocks - is key to the observed differences.

These differences in dynamics under the two monetary regimes make one wonder what would have happened if the transition between them had occurred at a different time, under different circumstances. To analyze this question we construct counterfactual histories that simulate how alternative monetary policy configurations would have affected the performance of the Brazilian economy in response to the estimated structural shocks.

Our results suggest that maintaining the currency peg after the first quarter of 1999 would have been come at a great cost. ${ }^{7}$ Although it is always possible to avoid an abrupt exchange rate devaluation in the model, our counterfactual analysis suggests that this would have required extremely high interest rates for several quarters. As a result, economic activity would have contracted sharply. Despite the fact that the model abstracts from some important dimensions, such as fiscal policy, it seems plausible to conclude that keeping the peg after the first quarter of 1999 would have been essentially impossible.

In a second counterfactual analysis, we simulate an acceleration of the pace of devaluation of the exchange rate crawling peg after the Asian Crisis, from approximately $7 \%$ to $14 \%$ per year. In this

\footnotetext{
${ }^{6}$ For recent papers on changes in monetary policy in Brazil since the implementation of the inflation targeting regime, see Berriel et al. (2013), Carvalho et al. (2013) e Gonçalves (2015).

${ }^{7}$ Our evaluation of the costs and benefits of alternative histories is deliberately informal and need not coincide with what would be implied by a formal welfare analysis based on the structure of the model. We proceed in this manner to relate the evaluation of different alternatives with what we take to be the "common sense" among participants of this debate in Brazil.
} 
case, Brazil would have experienced higher inflation, higher nominal and real interest rates, and weaker economic activity.

Finally, results from a third counterfactual simulation suggest that the first semester of 1998 may have offered the ideal window for a relatively smooth transition from the currency peg rate to the inflation targeting regime with a floating exchange rate.

The paper proceeds as follows. Section 2 presents the model and explains how its solution is cast in a state-space representation. The subsequent section provides details of the methodology and data used to estimate the model. Sections 4 and 5 present results of the estimated model and the simulated counterfactual histories, respectively. The last section concludes. In an attempt to shorten the paper and make it less arid, we defer the technical and methodological details to the Appendix, whenever possible.

\section{Model}

Our main reference is the (semi-)small open economy new Keynesian model of Justiniano and Preston (2010). A representative consumer derives utility and forms habits through the consumption of domestic and imported goods and services ("goods" or "products"). She also incurs disutility from supplying labor to domestic producers. In order to smooth consumption, she can resort to domestic bonds that yield the nominal interest rate set by the CBB and to bonds traded abroad, which earn an interest rate determined in the international market plus a premium that depends on Brazil's net foreign asset position.

Firms operate under monopolistic competition and are divided into two groups. Domestic producers employ labor to produce their goods using a technology that is subject to productivity shocks. The other group comprises retail firms that import their products, differentiate them at no extra cost, and sell them in the domestic market. All firms reevaluate their prices infrequently, and otherwise index their prices to past inflation.

The main modification we make to the model is the introduction of two distinct monetary regimes, in the spirit of Cúrdia and Finocchiaro (2013). In the first regime, the interest rate defined by the CBB responds to departures of the nominal exchange rate from a target that may evolve over time, interpreted as the center of the exchange rate band specified by the central bank. In the second regime, the CBB responds to deviations of inflation from its target, which may also vary over time. Following the approach advocated by Woodford (2003), we work with the cashless limit of a monetary economy. 


\subsection{Representative consumer}

The representative Brazilian consumer maximizes expected utility

$$
E_{0} \sum_{t=0}^{\infty} \beta^{t} \Gamma_{t}\left[\frac{\left(C_{t}-H_{t}\right)^{1-\sigma}}{1-\sigma}-\frac{N_{t}^{1+\varphi}}{1+\varphi}\right]
$$

subject to the budget constraint presented below. The $\Gamma_{t}$ term is a preference shock, $H_{t} \equiv h C_{t-1}$ is the "stock" of consumption habits (taken as given by the agent) and $N_{t}$ is labor supply. The parameter $\beta<1$ is the subjective time discount factor, and the parameters $\sigma$ and $\varphi$ are, respectively, the inverse of the elasticity of intertemporal substitution and the inverse of the (Frisch) elasticity of labor supply. The operator $E_{t}$ denotes expectations conditional on information available at time $t$.

Aggregate consumption is given by:

$$
C_{t}=\left[(1-\alpha)^{\frac{1}{\eta}} C_{D, t}^{\frac{\eta-1}{\eta}}+\alpha^{\frac{1}{\eta}} C_{I, t}^{\frac{\eta-1}{\eta}}\right]^{\frac{\eta}{1-\eta}}
$$

where $\eta$ is the elasticity of substitution between domestic and imported goods and $\alpha$ is the share of imported goods in total consumption - a measure of the degree of openness of the economy. $C_{D, t}$ and $C_{I, t}$ are the composites of domestic and imported goods, respectively, obtained through the aggregation of the different varieties $C_{D, t}(i)$ e $C_{I, t}(i)$ :

$$
C_{D, t}=\left[\int_{0}^{1} C_{D, t}(i)^{\frac{\varepsilon-1}{\varepsilon}} d i\right]^{\frac{\varepsilon}{\varepsilon-1}}, \quad C_{I, t}=\left[\int_{0}^{1} C_{I, t}(i)^{\frac{\varepsilon-1}{\varepsilon}} d i\right]^{\frac{\varepsilon}{\varepsilon-1}} .
$$

The elasticity of substitution between varieties with the same origin is given by $\varepsilon$.

To her dismay, the representative Brazilian consumer faces the following budget constraint:

$$
P_{t} C_{t}+D_{t}+S_{t} B_{t}=D_{t-1} R_{t-1}+S_{t} B_{t-1} R_{t-1}^{*} \Phi_{t-1}\left(\frac{S_{t-1} B_{t-1}}{P_{t-1} Y}\right)+W_{t} N_{t}+\Pi_{D, t}+\Pi_{I, t},
$$

where $S_{t}$ is the nominal exchange rate, quoted in domestic currency units ("Reais") per unit of foreign currency ("Dollars"), $D_{t}$ are ("domestic") bonds denominated in Reais and $B_{t}$ are Dollar-denominated ("foreign") bonds with gross interest rates given, respectively, by $R_{t}$ and $R_{t}^{*} \Phi_{t}\left(\frac{S_{t} B_{t}}{P_{t} Y}\right), W_{t}$ is the nominal wage, $\Pi_{D, t}$ and $\Pi_{I, t}$ are the profits of domestic producers and importers, respectively, $Y$ is the steadystate level of output, and $P_{t}$ is the price index associated with the consumption aggregator, to be defined below. The consumer also faces a standard "no-Ponzi" constraint.

The interest rate on foreign bonds $B_{t}$ is given by the combination of the international interest rate $R_{t}^{*}$ and a wedge that depends on Brazil's net foreign asset position, which can be interpreted as a risk 
premium associated with external indebtedness. This premium is given by the function $\Phi_{t}(\cdot):{ }^{8}$

$$
\Phi_{t}\left(Z_{t}\right)=\exp \left[-\chi Z_{t}+\phi_{t}\right]
$$

where $\phi_{t}$ is a risk-premium shock.

The assumption that the interest rate on foreign bonds depends positively on the level of external indebtedness guarantees the stationarity of the model. ${ }^{9}$ Furthermore, it allows us to introduce a shock that is needed for the estimation of the model, and which has the advantage of being interpreted as a deviation from the standard uncovered interest rate parity condition (see below).

The optimal allocation of consumption in each category of goods (domestic and imported) implies the following demands for the aggregate imported and domestic products:

$$
C_{D, t}=(1-\alpha)\left(\frac{P_{D, t}}{P_{t}}\right)^{-\eta} C_{t} \quad \text { and } \quad C_{I, t}=\alpha\left(\frac{P_{I, t}}{P_{t}}\right)^{-\eta} C_{t}
$$

and the following demands for each variety :

$$
C_{D, t}(i)=\left(\frac{P_{D, t}(i)}{P_{D, t}}\right)^{-\varepsilon} C_{D, t} \quad \text { and } \quad C_{I, t}(i)=\left(\frac{P_{I, t}(i)}{P_{I, t}}\right)^{-\varepsilon} C_{I, t} .
$$

The varieties of goods and services are imperfect substitutes, and so firms retain some market power. This is reflected in negatively sloped demand curves (equation (1)).

The price indices by product origin are given by:

$$
P_{D, t}=\left(\int_{0}^{1} P_{D, t}(i)^{1-\varepsilon} d i\right)^{\frac{1}{1-\varepsilon}} \quad \text { e } P_{I, t}=\left(\int_{0}^{1} P_{I, t}(i)^{1-\varepsilon} d i\right)^{\frac{1}{1-\varepsilon}}
$$

and the aggregate price index for the domestic economy is given by:

$$
P_{t}=\left[(1-\alpha) P_{D, t}^{1-\eta}+\alpha P_{I, t}^{1-\eta}\right]^{\frac{1}{1-\eta}} .
$$

The remaining first-order conditions for the representative consumer's optimization problem are: ${ }^{10}$

$$
\begin{gathered}
W_{t} / P_{t}=N_{t}^{\varphi}\left(C_{t}-h C_{t-1}\right)^{\sigma}, \\
\Gamma_{t}\left(C_{t}-h C_{t-1}\right)^{-\sigma}=\beta E_{t}\left[\Gamma_{t+1}\left(C_{t+1}-h C_{t}\right)^{-\sigma} R_{t} \frac{P_{t}}{P_{t+1}}\right], \\
\Gamma_{t}\left(C_{t}-h C_{t-1}\right)^{-\sigma}=\beta E_{t}\left[\Gamma_{t+1}\left(C_{t+1}-h C_{t}\right)^{-\sigma} R_{t}^{*} \Phi_{t}\left(\frac{S_{t} B_{t}}{P_{t} Y}\right) \frac{S_{t+1}}{S_{t}} \frac{P_{t}}{P_{t+1}}\right] .
\end{gathered}
$$

\footnotetext{
${ }^{8}$ We assume that the representative agent takes this risk premium as given when making her consumption and portfolio decisions.

${ }^{9}$ For an analysis of alternative ways to induce stationarity in small open economy models, see Schmitt-Grohe and Uribe (2003).

${ }^{10}$ The optimal choices must also satisfy a standard transversality condition.
} 
Equation (2) determines the labor supply, and (3) and (4) are standard Euler equations. These last two equations can be combined to obtain a risk-premium-adjusted uncovered interest parity condition:

$$
E_{t}\left[\Gamma_{t+1}\left(C_{t+1}-h C_{t}\right)^{-\sigma} \frac{P_{t}}{P_{t+1}}\left(R_{t}^{*} \Phi_{t}\left(\frac{S_{t} B_{t}}{P_{t} Y}\right) \frac{S_{t+1}}{S_{t}}-R_{t}\right)\right]=0
$$

\subsection{Domestic producers}

There is a continuum of domestic producers operating under monopolistic competition, indexed by $i \in[0,1]$. Each company employs labor to produce a differentiated good/service $y_{D, t}(i)$. Production technologies are subject to a common productivity shock, given by $A_{t}$ :

$$
y_{D, t}(i)=A_{t} N_{t}(i)
$$

For ease of exposition, we denote the real marginal cost, which is the same for all domestic producers, as:

$$
M C_{D, t}=\frac{W_{t}}{A_{t} P_{D, t}}
$$

Hence, we can write firm $i$ 's profits as:

$$
\Pi_{D, t}(i)=y_{D, t}(i)\left(P_{D, t}(i)-P_{D, t} M C_{D, t}\right) .
$$

Firms reoptimize their prices infrequently, as in Calvo (1983). For each firm, this happens with probability $1-\theta_{D}$ per period, independently of what happens to other firms. Therefore, in each period a fraction $\left(1-\theta_{D}\right)$ of firms reoptimizes their prices, while the remaining fraction $\left(\theta_{D}\right)$ follows an indexation rule. Specifically, firms that do not reoptimize in period $t$ adjust their previous prices according to:

$$
P_{D, t}(i)=P_{D, t-1}(i)\left(\frac{P_{D, t-1}}{P_{D, t-2}}\right)^{\delta_{D}}
$$

where the parameter $\delta_{D}$ determines the degree of indexation to past inflation.

All firms that reoptimize in period $t$ face the same intertemporal problem and chose the same price $X_{D, t}(i)=X_{D, t}$. Hence, the price index for domestic products evolves according to:

$$
P_{D, t}=\left[\left(1-\theta_{D}\right) X_{D, t}^{(1-\varepsilon)}+\theta_{D}\left(P_{D, t-1}\left(\frac{P_{D, t-1}}{P_{D, t-2}}\right)^{\delta_{D}}\right)^{1-\varepsilon}\right]^{1 /(1-\varepsilon)}
$$

Firms sell their products in both the domestic and international markets. We assume that the external demand has the same functional form as the domestic demand (1), so that a firm that reoptimized 
its price in the period $t$ faces the following sequence of demands:

$$
y_{D, t+\tau \mid t}=\left(\frac{X_{D, t}}{P_{D, t+\tau}}\left(\frac{P_{D, t+\tau-1}}{P_{D, t-1}}\right)^{\delta_{D}}\right)^{-\varepsilon}\left(C_{D, t+\tau}+C_{D, t+\tau}^{*}\right),
$$

where $C_{D, t+\tau}^{*}$ is the external aggregate demand for domestic products (to be detailed below).

Taking price rigidity into account, a firm selecting the optimal price in period $t$ maximizes the present discounted value of its expected profits:

$$
E_{t} \sum_{\tau=0}^{\infty} \theta_{D}^{\tau} \Theta_{t, t+\tau} y_{D, t+\tau \mid t}\left[X_{D, t}\left(\frac{P_{D, t+\tau-1}}{P_{D, t-1}}\right)^{\delta_{D}}-P_{D, t+\tau} M C_{D, t+\tau}\right],
$$

subject to the sequence of demands given by equation (5), where $\Theta_{t, t+\tau}=\beta^{\tau} \frac{\Gamma_{t+\tau}}{\Gamma_{t}} \frac{P_{t}}{P_{t+\tau}} \frac{U_{c, t+\tau}}{U_{c, t}}$ is the nominal discount stochastic factor of the representative consumer. ${ }^{11}$

\subsection{Importing retail firms}

Retail firms import goods acquired at prices determined in the international market, and transform them into differentiated goods to be sold in the domestic market. For simplicity, we assume that this differentiation is done at no cost. The retail sector is characterized by monopolistic competition, so that each firm has some market power to set prices. These are set in local currency, and are subject to infrequent adjustments and indexation to past inflation. This leads to an imperfect passthrough from international prices and nominal exchange rate movements to consumer prices.

All importing firms which re-optimize in period $t$ face the same intertemporal problem and chose the same price $X_{I, t}(i)=X_{I, t}$. Hence, the aggregate price index for imported goods sold in the domestic market evolves according to:

$$
P_{I, t}=\left[\left(1-\theta_{I}\right) X_{I, t}^{(1-\varepsilon)}+\theta_{I}\left(P_{I, t-1}\left(\frac{P_{I, t-1}}{P_{I, t-2}}\right)^{\delta_{I}}\right)^{1-\varepsilon}\right]^{1 /(1-\varepsilon)}
$$

where $\theta_{I}$ is the price rigidity parameter and $\delta_{I}$ is the indexation parameter.

The optimization problem of retail firms is also analogous to that of domestic producers. Subject to the demand sequence

$$
C_{I, t+\tau \mid t}=\left(\frac{X_{I, t}}{P_{I, t+\tau}}\left(\frac{P_{I, t+\tau-1}}{P_{I, t-1}}\right)^{\delta_{I}}\right)^{-\varepsilon} C_{I, t+\tau}
$$

\footnotetext{
${ }^{11}$ Because we assume incomplete markets, the reader who is familiar with this type of model may question the use of the stochastic discount factor for the valuation of future stream of profits. Although arbitrary, this assumption is innocuous, because it does not affect the first-order approximation of the model that we shall rely on. We would obtain the same results under the assumption that future profits are discounted at the nominal interest rate.
} 
firms maximize the present discounted value of expected profits

$$
E_{t} \sum_{\tau=0}^{\infty} \theta_{I}^{\tau} \Theta_{t, t+\tau} C_{I, t+\tau \mid t}\left[X_{I, t}\left(\frac{P_{I, t+\tau-1}}{P_{I, t-1}}\right)^{\delta_{I}}-S_{t+\tau} P_{t+\tau}^{*}\right],
$$

where $P_{t}^{*}$ is the price of imported products in the international market.

\subsection{Law of one price, exchange rates and terms of trade}

For later use, here we define some objects of interest. The real exchange rate $Q_{t}$ is given by the ratio between international and domestic prices converted to the same currency:

$$
Q_{t} \equiv S_{t} P_{t}^{*} / P_{t}
$$

The terms of trade $T o T_{t}$ are defined as the relative price of Brazil's imports and exports: ${ }^{12}$

$$
\operatorname{ToT}_{t}=P_{I, t} / P_{D, t}
$$

Lastly, we define the ratio between international prices converted to Reais and the prices of imported goods in the domestic market:

$$
\Psi_{I, t}=S_{t} P_{t}^{*} / P_{I, t}
$$

The variable $\Psi_{I, t}$ measures deviations from the Law of One Price for imported goods.

\subsection{Monetary policy}

Monetary policy is characterized by a distinct interest rate rule for each regime. In the first part of the sample, corresponding to the currency peg regime, we explicitly model the reaction of the CBB to deviations of the nominal exchange rate from its desired level. In the second part of the sample, corresponding to the inflation targeting regime, the main characteristic of the interest rate rule is the response to deviations of inflation from target. For ease of exposition, here we describe the interest rate rule in a heuristic manner, and postpone the presentation of the equations to Section 2.8, where we present the first-order approximation of the model.

\subsubsection{Crawling peg regime}

During the first 12 months after the launching of the Real Plan in July 1994, the Brazilian Real was allowed to float within relatively wide bands. In June 1995, the CBB adopted a system of tight exchange rate bands - the so-called "mini-bands" - which were then readjusted periodically at an essentially

\footnotetext{
${ }^{12}$ Note that this is the inverse of the more usual terms of trade measure. We adopt this convention to make it easier to compare our results to those of Justiniano and Preston (2010).
} 


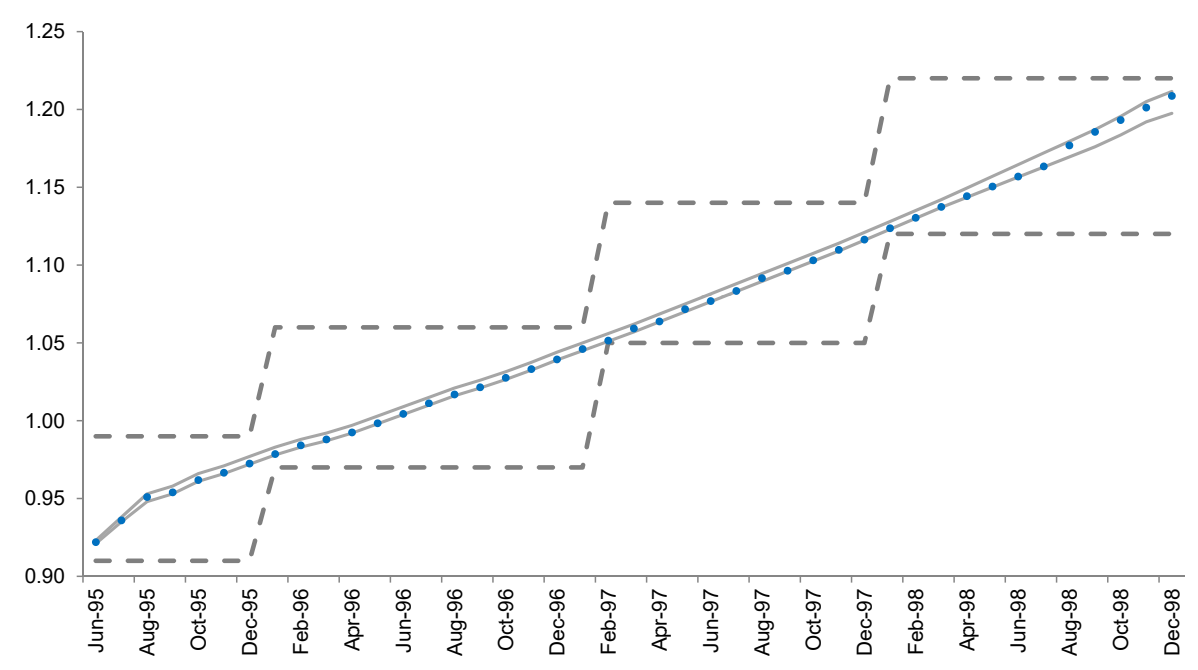

Figure 1: Exchange rate mini- and macro-bands (solid and dashed lines, respectively) and the evolution of the exchange rate in $\mathrm{R} \$ / \mathrm{US} \$$ (blue dots).

deterministic devaluation pace. ${ }^{13}$ In order to keep the nominal exchange rate within the specified limits, the $\mathrm{CBB}$ resorted to interventions in the foreign exchange market and changes in the policy rate (in a context of imperfect capital mobility). Figure 1 shows the evolution of the nominal exchange rate in $\mathrm{R} \$ / \mathrm{US} \$$, of the upper and lower limits of the mini-bands and of the macro-bands from June 1995 to December 1998.

We follow Cúrdia and Finocchiaro (2013) in assuming that monetary policy during the crawling peg regime is described by a standard interest rate rule. More specifically, it features the usual responses to inflation and economic activity, but is modified to include deviations of the nominal exchange rate from the target specified by the CBB. This allows the CBB to react to exchange rate pressures, and is compatible with the behavior of the nominal exchange rate in that period.

\subsubsection{Inflation targeting regime}

Monetary policy in the inflation targeting regime follows a standard interest rate rule with a small modification. Despite the floating exchange rate, the $\mathrm{CBB}$ is allowed to respond to changes in the nominal exchange rate. Other than that, the interest rate responds to economic activity and deviations of inflation from its target.

\subsection{Foreign block}

The domestic economy is assumed to be small enough not to affect the world economy. For simplicity, the latter is assumed to evolve according to a first-order vector autoregressive model (VAR). ${ }^{14}$ The

\footnotetext{
${ }^{13}$ The so-called "macro-bands" continued to exist, but lost any practical relevance.

${ }^{14}$ The VAR(1) coefficients are estimated separately, and kept fixed during the estimation of the DSGE model.
} 
variables included in the VAR are output $Y_{t}^{*}$, inflation $\pi_{t}^{*} \equiv \log \left(P_{t}^{*} / P_{t-1}^{*}\right)$ and the foreign interest rate $i_{t}^{*} \approx \log \left(R_{t}^{*}\right)$. The VAR shocks are denoted by $\varepsilon_{y}^{*}, \varepsilon_{\pi}^{*}$ and $\varepsilon_{i}^{*}$.

To allow identification of a foreign monetary shock, we impose the usual Cholesky ordering, with the foreign interest rate placed last. Therefore, the $\operatorname{VAR}(1)$ can be described as

$$
A_{0}\left[\begin{array}{c}
Y_{t}^{*} \\
\pi_{t}^{*} \\
i_{t}^{*}
\end{array}\right]=A_{1}\left[\begin{array}{c}
Y_{t-1}^{*} \\
\pi_{t-1}^{*} \\
i_{t-1}^{*}
\end{array}\right]+\left[\begin{array}{c}
\varepsilon_{y}^{*} \\
\varepsilon_{\pi}^{*} \\
\varepsilon_{i}^{*}
\end{array}\right]
$$

where the coefficient matrices are

$$
A_{0}=\left[\begin{array}{ccc}
1 & 0 & 0 \\
a_{0, \pi y} & 1 & 0 \\
a_{0, i y} & a_{0, i \pi} & 1
\end{array}\right] \quad A_{1}=\left[\begin{array}{ccc}
a_{1, y y} & a_{1, y \pi} & a_{1, y i} \\
a_{1, \pi y} & a_{1, \pi \pi} & a_{1, \pi i} \\
a_{1, i y} & a_{1, i \pi} & a_{1, i i}
\end{array}\right]
$$

\subsection{General equilibrium}

Equilibrium in the market for domestic goods and services requires equality between domestic production and the sum of domestic consumption and exports:

$$
Y_{t}=C_{D, t}+C_{D, t}^{*}
$$

where we assume that the international demand for domestic products is given by

$$
C_{D, t}^{*}=\left(\frac{P_{D, t} / S_{t}}{P_{t}^{*}}\right)^{-\eta} Y_{t}^{*}
$$

The equation above reflects the assumption, already embbeded in equation (5), that the export prices of domestic products are the same as the prices in the domestic market, converted to foreign currency using the nominal exchange rate for each period.

Additionally, we assume that domestic bonds are in zero net supply, so that $D_{t}=0$ for all periods. The remaining equilibrium conditions are standard.

\subsection{First-order approximation of the model}

As in most of the literature on DSGE models, we work with a first-order approximation of the equilibrium conditions around a non-stochastic steady state characterized by zero inflation - and balanced trade. The complete set of log-linearized equations is shown in the Appendix. As a general rule, lowercase letters indicate deviations of the respective variables from its steady state value. In most cases, the deviation is logarithmic, but in some cases it is in levels.

Regarding monetary policy, as detailed in Section 2.5 the model specifies one interest rate rule for each regime. These are the only equations that may vary across regimes. The rule for the crawling peg 
regime is given by

$$
i_{t}=\rho_{i, 1}^{F X} i_{t-1}+\rho_{i, 2}^{F X} i_{t-2}+\left(1-\rho_{i, 1}^{F X}-\rho_{i, 2}^{F X}\right)\left(\lambda_{\pi}^{F X} \pi_{t}+\lambda_{y}^{F X} y_{t}+\lambda_{s}^{F X}\left(s_{t}-s_{c, t}\right)\right)+\varepsilon_{i, t}^{F X}
$$

where $\pi_{t} \equiv \log \left(P_{t} / P_{t-1}\right)$ e $s_{c, t}$ denotes the exchange rate target. We included an interest rate lag to allow for policy inertia. Finally, $\varepsilon_{i, t}^{F X}$ is a shock in the interest rate rule, which can be interpreted as a non-systematic component of monetary policy.

For the inflation targeting regime, we defined the rule: ${ }^{15}$

$$
i_{t}=\rho_{i, 1}^{I T} i_{t-1}+\rho_{i, 2}^{I T} i_{t-2}+\left(1-\rho_{i, 1}^{I T}-\rho_{i, 2}^{I T}\right)\left[\lambda_{\pi}^{I T}\left(\pi_{t}-\pi_{m, t}\right)+\lambda_{y}^{I T} y_{t}+\lambda_{s}^{I T} \Delta s_{t}\right]+\varepsilon_{i, t}^{I T},
$$

where $\Delta$ is the first-difference operator and $\pi_{m, t}$ is the inflation target.

\subsection{Shocks}

The model features eight structural shocks ${ }^{16}$ - five of them in the domestic economy and three related to the foreign block. The structural shocks related to the domestic economy are related to monetary policy $(i)$, preferences $(\gamma)$, technology $(a)$, risk premium $(\phi)$, and cost of imported goods $(c p) .{ }^{17}$ The last four shocks follow first-order autoregressive processes $(\operatorname{AR}(1))$, whereas the domestic monetary policy shock and foreign shocks are assumed to be i.i.d.:

$$
\begin{gathered}
a_{t}=\rho_{a} a_{t-1}+\sigma_{a} \epsilon_{a, t}, \\
\gamma_{t}=\rho_{\gamma} \gamma_{t-1}+\sigma_{\gamma} \epsilon_{\gamma, t}, \\
\varepsilon_{c p, t}=\rho_{c p} \varepsilon_{c p, t-1}+\sigma_{c p} \epsilon_{c p, t}, \\
\phi_{t}=\rho_{\phi} \phi_{t-1}+\sigma_{\phi} \epsilon_{\phi, t}, \\
\varepsilon_{i, t}^{r}=\sigma_{i, r} \epsilon_{i, t}, \quad r=F X, I T, \\
\varepsilon_{y^{*}, t}=\sigma_{y^{*}} \epsilon_{y^{*}, t}, \quad \varepsilon_{\pi^{*}, t}=\sigma_{\pi^{*}} \epsilon_{\pi^{*}, t}, \quad \varepsilon_{i^{*}, t}=\sigma_{i^{*}} \epsilon_{i^{*}, t} .
\end{gathered}
$$

The $\epsilon$ innovations are cross-sectionally independent i.i.d. $N(0,1)$.

\footnotetext{
${ }^{15}$ This rule is similar to those found in Cúrdia and Finocchiaro (2013) for the case of Sweden, Del Negro and Schorfheide (2009) for Chile, and Justiniano and Preston (2010) for Australia, Canada and New Zealand.

${ }^{16}$ This count leaves aside shocks to the inflation and exchange rate targets, which are only used in the counterfactual experiments. For details, see Sections 3.1 e 5 .

${ }^{17}$ We follow Justiniano and Preston (2010) and append a cost-push shock to the Phillips curve for imported goods inflation.
} 


\subsection{Solution of the model and state-space representation}

The model equations in their (log-)linear form can be written as

$$
E_{t}\left\{f^{r}\left(\Upsilon_{t+1}, \Upsilon_{t}, \Upsilon_{t-1}, \epsilon_{t+1}, \epsilon_{t} ; \theta\right)\right\}=0, \quad r=F X, I T
$$

where $\theta$ is a vector collecting all structural parameters of the DSGE model, $\Upsilon_{t}$ is a vector containing its variables and $\epsilon_{t}$ is a vector with the aforementioned structural innovations. Regarding the assumption about expectations formation underlying the representation in (6), recall that the transition between regimes is assumed to be unanticipated.

We solve the model using the method proposed by Sims (2002), restricting the parameter space to exclude cases with multiple solutions or no (bounded) solution. The unique solution can be represented as:

$$
\Upsilon_{t}=A^{r}(\theta) \Upsilon_{t-1}+B^{r}(\theta) \epsilon_{t}, \quad r=F X, I T
$$

These equations comprise the reduced-form solution of the model, which takes the form of a VAR(1). They are the so-called transition equations.

The next step toward estimation of the model is to connect variables in $\Upsilon_{t}$ to observables through so-called observation (or measurement) equations. This completes the state-space representation of the model, composed of transition and observation equations.

The regime-specific transition equations are given by the reduced-form $\operatorname{VAR}(1)$ representation of the model (equation 7). The observation equations are the same for both regimes and are given by

$$
\Upsilon_{t}^{o b s}=C \Upsilon_{t}
$$

where $\Upsilon_{t}^{o b s}$ is the vector of observables, to be discussed in Section 3.1.

Given enough structural shocks and measurement errors in the observation equations, the Kalman filter can be used to construct the likelihood function for the vector of observables $\Upsilon_{t}^{o b s}$, for a given vector of parameters $\theta .{ }^{18}$

\section{Estimation}

Our model is composed of two sets of equations, one for the crawling peg regime and the other for the inflation targeting regime. The goal of the estimation is to extract information from the data about the structural parameters of the economy, grouped into the vector $\theta$, taking into account the change in regime that happened in the beginning of 1999.

In the econometrics literature on "structural breaks", a distinction is made between a "pure break",

\footnotetext{
${ }^{18}$ See, for example, Hamilton (2004).
} 
in which the whole vector of parameters of interest is subject to change, and a "partial break", in which only a few components of the vector of parameters may change. In our model, we face a partial break, because only the parameters referring to the monetary policy rule can vary between regimes. Therefore, we can rewrite the vector $\theta$ as

$$
\theta=\left(\theta_{0}, \theta_{F X}, \theta_{I T}\right)
$$

where $\theta_{0}$ collects the invariant parameters, $\theta_{F X}$ groups the parameters associated with the crawling peg regime, and $\theta_{I T}$ collects the parameters associated with the inflation targeting regime.

One option to estimate this model is to split the sample according to the two monetary regimes and carry out an estimation for each sub-sample. However, this approach is inefficient, because it ignores the fact that most parameters are invariant to the regime shift.

Cúrdia and Finocchiaro (2013) estimate an analogous DSGE model for Sweden, accounting for the shift from a fixed exchange rate regime to an inflation targeting regime with floating exchange rates, which took place in that country in the early 1990s. The authors suggest a simple way to account for the regime change and use the whole sample in the estimation, which is then carried out using Bayesian methods. We follow their methodology.

To lighten the exposition, we leave the details of the estimation - including specification of the prior distribution of the structural parameters - to the Appendix. In summary, the procedure consists in simulating a sample of the posterior distribution of the structural parameters, since it cannot be obtained in closed form. This distribution obtains from the combination of the prior distribution with the likelihood function of the model. This function is obtained by applying the Kalman filter to the state-space representation of the model. The only difference relative the standard procedure used to construct the likelihood function stems from the existence of two monetary regimes. This generates a shift in the state-space representation of the model when the inflation targeting regime with floating exchange rate is put in place. We deal with this break by following the approach suggested by Cúrdia and Finocchiaro (2013). This approach consists in: i) decomposing the likelihood function into parts corresponding to the sample periods defined by the two monetary regimes; and ii) concatenating the recursions of the Kalman filter so that iterations of the Kalman filter for the second part of the sample are initialized with the estimates for the state of the economy (and the associated uncertainty) that correspond to the last observation of the first part of the sample.

\section{$3.1 \quad$ Data}

The vector of observables $\Upsilon_{t}^{o b s}$ includes eight series: Domestic GDP, domestic interest rate, domestic inflation, terms of trade, nominal exchange rate, foreign GDP, foreign interest rate and foreign inflation:

$$
Y_{t}=\left(y_{t}, i_{t}, \pi_{t}, \text { tot }_{t}, s_{t}, y_{t}^{*}, i_{t}^{*}, \pi_{t}^{*}\right)
$$


Table 1 presents details of the series. Monthly series were converted into quarterly series, by taking averages $\left(t_{t} t_{t}\right),{ }^{19}$ end of period values $\left(s_{t}\right)$, or cumulating over the quarter $\left(\pi_{t}\right.$ e $\left.i_{t}\right)$. The sample ranges from the third quarter of 1995 to the second quarter of 2013. The period for the crawling peg regime ends in the fourth quarter of $1998 .^{20}$ For the foreign block, we use U.S. data.

Table 1: Data used in the estimation.

\begin{tabular}{clc}
\hline \hline & Série & Fonte \\
\hline$y_{t}$ & GDP at market prices, seasonally adjusted, quarterly & IBGE \\
$\pi_{t}$ & IPCA - General, monthly & IBGE \\
$i_{t}$ & Interest rate - SELIC, monthly & CBB \\
$t_{t} t_{t}$ & Terms of trade - Index, monthly & FUNCEX \\
$s_{t}$ & Nominal exchange rate - R/US - bid, monthly & CBB \\
$y_{t} *$ & USA Real GDP, seasonally adjusted, quarterly & FRED (St. Louis Fed) \\
$\pi_{t *}$ & USA CPI - All items, seasonally adjusted, quarterly & FRED (St. Louis Fed) \\
$i_{t}^{*}$ & USA 5-Year Treasury yield - constant maturity, e.o.p, quarterly & FRED (St. Louis Fed)
\end{tabular}

We filter the (log) GDP series with the Hodrik-Prescott filte, using a smoothing parameter of 1600 . With the exception of domestic inflation and the nominal exchange rate, we extract a log-linear trend from the series. ${ }^{21}$ Due to the way they enter the monetary policy rule, there is a complicating factor in using those two variables in the estimation. In the crawling peg regime, the CBB reacts to deviations of the exchange rate from its desired level, while in the inflation targeting regime the CBB reacts to deviations of inflation from target. However, there is no explicit inflation target during the crawling peg regime, as well as no explicit exchange rate target in the inflation targeting regime. A possible solution would be to specify the stochastic process for these variables (targets for nominal exchange rate and inflation) and treat them as unobservables outside of their respective regimes. For simplicity, we decided not to include them as observables and adjusted the nominal exchange rate and domestic inflation series to incorporate this information in an approximate manner.

For the nominal exchange rate, we fit a log-linear trend to the center of the exchange rate bands that were in place during the crawling peg regime. We then extrapolate this trend for the whole sample

\footnotetext{
${ }^{19}$ The terms of trade index produced by FUNCEX is given by the ratio between the price of exports and the price of imports. To make this measure consistent with the definition of terms of trade in the model, the estimation uses the inverse of this index.

${ }^{20}$ Because the floating exchange rate was adopted in the first half of January 1999, it seems reasonable to consider the first quarter of 1999 as a part of the new monetary regime.

${ }^{21}$ The extraction of a log-linear trend from foreign GDP delivers an output drop in response to a contractionary foreign monetary policy shock, identified in the small VAR used to model the foreign block. The same does not happen when we use a Hodrick-Prescott filter. However, in both specifications there is the so-called "prize puzzle" - i.e., inflation goes up after an identified monetary tightening. In future research it would be interesting to replace the small VAR with a model that allows for a better identification of foreign monetary policy shocks, such as Bernanke et al. (2005).
} 
period and subtract it from the (log of the) nominal exchange rate. Because the center of the exchange rate band evolved in an approximately log-linear manner, in the first part of the sample the series of the nominal exchange rate used in the estimation is very close to its logarithmic deviation from the center of the exchange rate band, which is the object that enters the CBB's reaction function. ${ }^{22}$ In the inflation targeting regime, the monetary policy rule includes the change in the nominal exchange rate, so this transformation produces an approximate measure of the relevant variable. ${ }^{23}$

For domestic inflation, we demean the whole series. ${ }^{24}$ This results in the loss of variability of the official inflation target observed in the beginning of this regime, before the convergence to the $4.5 \%$ target in $2005 .^{25}$

Finally, an observation regarding the use of a 5-year interest rate in the VAR model of the U.S. economy, instead of a short-term rate. This is done to avoid the zero lower bound on short-term interest rates and thus be able to extend the sample beyond the end of 2008. The reasons for selecting a 5year rate are twofold. Swanson and Williams (2014) show that, even after the Fed had cut the federal funds rate to essentially zero, yields on 5-year (and longer-dated) treasuries continued to respond to macroeconomic surprises in ways that resembled the responses during periods in which interest rates were farther away from zero. Additionally, when we estimate the VAR of the foreign block with the 5 -year rate using the pre-2008 sample, we obtain dynamics that are quite similar to a traditional VAR using 3-month interest rates as a measure of $i_{t}^{*}{ }^{26}$

\section{Results}

\subsection{Posterior distributions}

We are particularly interested in possible differences in the monetary policy rule associated with each regime, summarized in Table $2 .{ }^{27}$ The parameters of the two monetary policy rules reflect characteristics that one would expect for the different regimes. In the crawling peg regime, we point out the response of the interest rate to deviations of the nominal exchange rate from trend $\left(\lambda_{s}\right)$, reflecting the focus of the $\mathrm{CBB}$ on nominal exchange rate stability.

In the inflation targeting regime, we highlight the response of interest rates to deviations of inflation from target $\left(\lambda_{\pi}\right)$, the greater persistence of the interest rate $\left(\rho_{i, 1}\right.$ e $\left.\rho_{i, 2}\right)$, and the smaller magnitude

\footnotetext{
${ }^{22}$ A relevant question here pertains to the expectations regarding the evolution of the exchange rate bands. Given that this is a rational expectations model, estimating it with an explicit stochastic process for the nominal exchange rate target (and including it as an observable) would handle this dimension.

${ }^{23}$ The subtraction of the log-linear trend from the nominal excghange rate adds a constant to the first difference of the transformed series, albeit a small one.

${ }^{24}$ Cúrdia and Finocchiaro (2013) also use this transformation.

${ }^{25}$ We also carried out an estimation in which we subtracted the time-series average of inflation targets from domestic inflation, and results changed only slightly.

${ }^{26}$ See Vilela (2014) for more details.

${ }^{27}$ In the Appendix we report additional estimation results.
} 
Table 2: Monetary policy rule: Comparison across regimes

\begin{tabular}{ccccc}
\hline \hline & \multicolumn{2}{c}{ Crawling peg } & \multicolumn{2}{c}{ Inflation targeting } \\
Parameter & Mode & $\begin{array}{c}\text { Standard } \\
\text { deviation }\end{array}$ & Mode & $\begin{array}{c}\text { Standard } \\
\text { deviation }\end{array}$ \\
\hline$\rho_{i, 1}$ & 0.31 & 0.10 & 0.54 & 0.08 \\
$\rho_{i, 2}$ & 0.33 & 0.10 & 0.30 & 0.08 \\
$\lambda_{\pi}$ & 1.52 & 0.35 & 1.99 & 0.41 \\
$\lambda_{y}$ & 0.28 & 0.10 & 0.70 & 0.15 \\
$\lambda_{s}, \lambda_{\Delta s}$ & 1.96 & 0.47 & 0.31 & 0.09 \\
$\sigma_{i}$ & 1.73 & 0.34 & 0.79 & 0.09 \\
\hline
\end{tabular}

of innovations in the interest rate rule $\left(\sigma_{i}\right)$, which suggest greater predictability of monetary policy decisions.

It is interesting to point out that the differences in estimates across regimes are similar to those found by Cúrdia and Finocchiaro (2013) for Sweden. The only exception is the coefficient on output, for which Cúrdia and Finocchiaro (2013) found a reduction when moving from a currency peg to the inflation targeting regime. In contrast, our estimates point to a market increase in the sensitivity of the interest rate to the level of economic activity in the inflation targeting regime.

Finally, the results obtained for the invariant parameters are plausible. In some cases, they are very similar to those found in other DSGE models estimated for small open economies. For example, Justiniano and Preston (2010) also find low values for the inflation indexation parameters in Phillips curves for both domestic goods inflation and imported goods inflation.

\subsection{Shock propagation}

The importance of the monetary policy rule associated with each regime becomes evident when we analyze the impact and propagation of shocks. To do so, we compare impulse response functions across regimes and observe that the dynamics of macroeconomic variables in response to shocks display important quantitative and qualitative differences. After that, using a variance decomposition, we show that these differences are also visible in the contribution of each structural shock to the volatility of macroeconomic variables in the model. In all such exercises, we use the mode of the posterior distribution to fix the values for the structural parameters. To shorten the exposition, we present results for a few shocks only. 


\subsubsection{Contractionary domestic monetary policy shock}

We start with the effects of domestic monetary policy shocks. It is important to keep in mind that the analysis of these shocks in the crawling peg regime must be done with care. Due to the focus of the CBB in maintaining the nominal exchange rate at an essentially predetermined level, the exogenous increase in the interest rate is almost immediately reversed to bring the exchange rate back to target. In spite of this fact, the exercise is useful to illustrate the transmission of shocks in the economy.
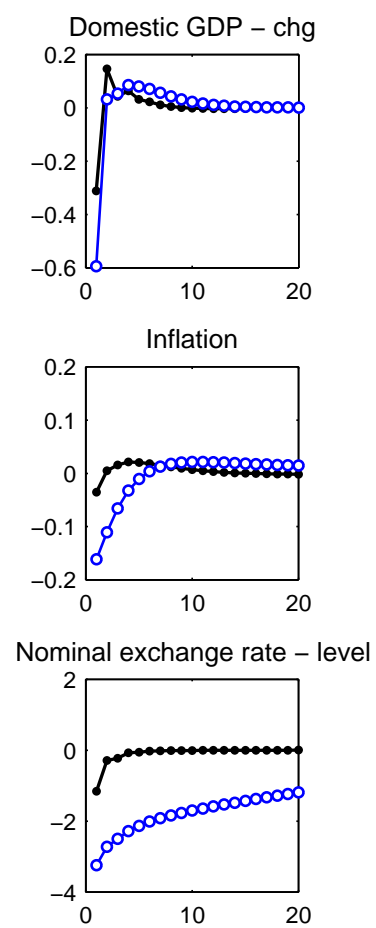

Nominal exchange rate - chg

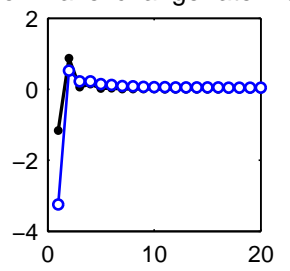

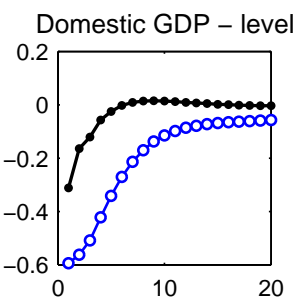

Inflation - domestic goods

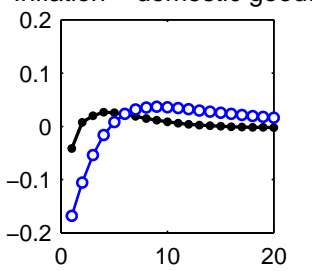

Real exchange rate - level
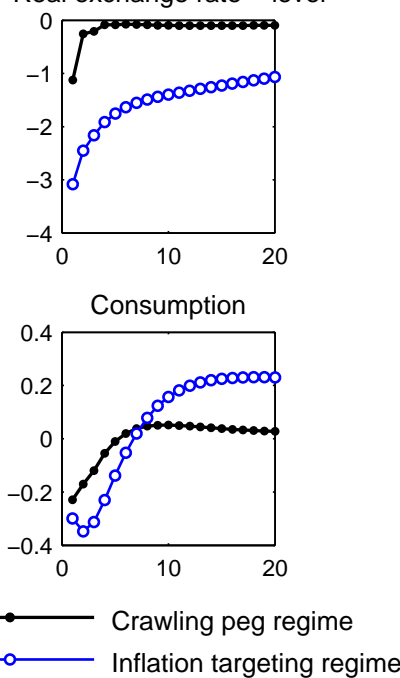
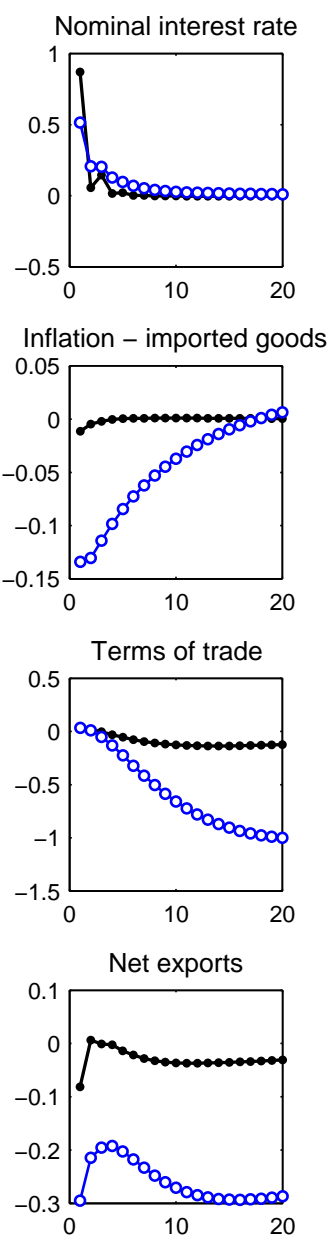

Figure 2: Effects of a contractionary domestic monetary policy shock, in percentage points.

Figure 2 shows the response of several variables to a contractionary domestic monetary policy shock in the crawling peg (black lines with solid circles) and inflation targeting (blue lines with hollow circles) regimes. In each case the innovation is equivalent to one standard deviation (i.e., the value of $\sigma_{i}$ in each regime). For most variables, the pattern of the response is similar in qualitative terms. In response to a monetary tightening, the exchange rate increases in nominal and real terms, and the various inflation measures decline. Output decreases as consumption and net exports contract. However, it is important 
to point out that there are meaningful quantitative differences across regimes, with significantly stronger responses in the inflation targeting regime. These differences do not stem from the size of the shock, which is larger in the crawling peg regime (see Table 2), but from the way in which shocks are propagated in each regime.

\subsubsection{Contractionary foreign monetary policy shock}

The effects of a contractionary foreign monetary policy shock are shown in Figure 3. In this case, there is pressure for the domestic currency to depreciate. In the crawling peg regime, we see a marked increase in the interest rate set by the $\mathrm{CBB}$, in an attempt to keep the nominal exchange rate close to the desired level. This causes a reduction in consumption and GDP.
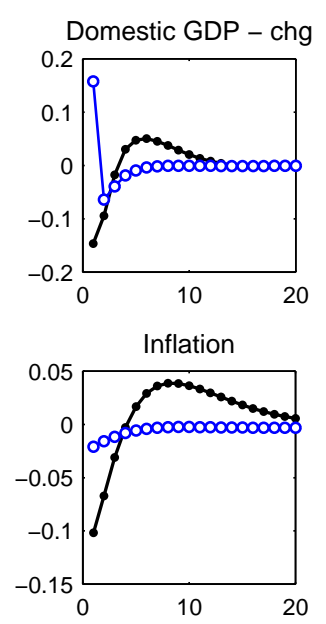

Nominal exchange rate - level

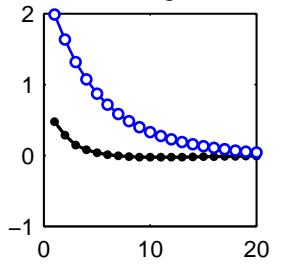

Nominal exchange rate - chg

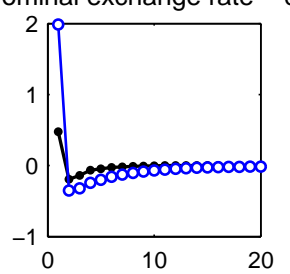

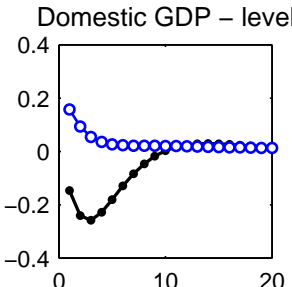

Inflation - domestic goods

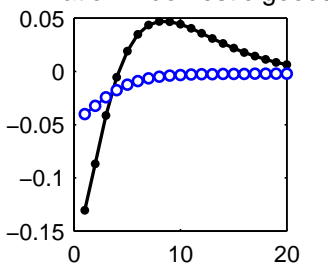

Real exchange rate - level
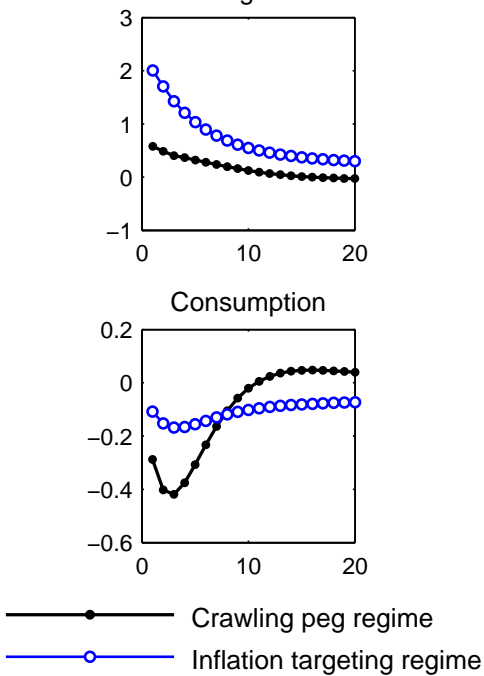
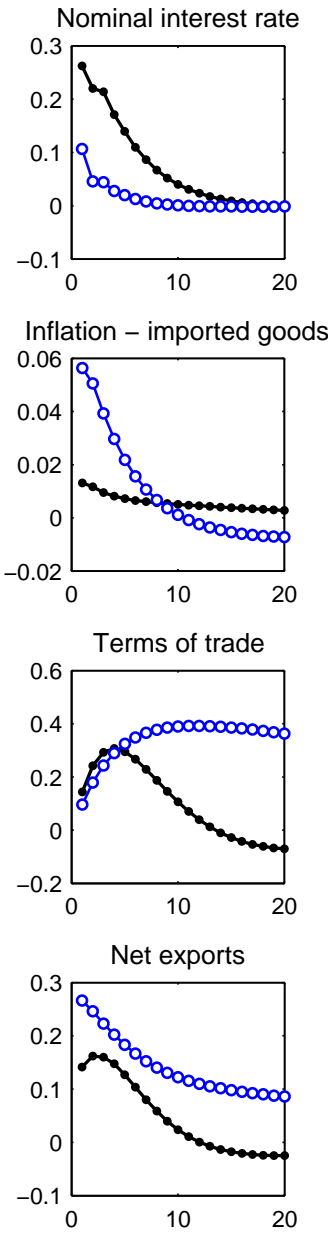

Figure 3: Effects of a contractionary foreign monetary policy shock, in percentage points.

In the inflation targeting regime, the role of floating exchange rates as shock absorbers - already pointed out by Friedman (1966) - is quite visible. Indeed, results show a relatively muted response of 
the domestic interest rate, GDP, inflation and consumption. This relative stability contrasts with the greater depreciation of the nominal and real exchange rates relative to the crawling peg regime.

A slightly counterintuitive result is the increase in domestic GDP under the inflation targeting regime in response to a foreign monetary policy tightening. Monacelli (2004) argues that, under a floating exchange rate, a monetary contraction originated abroad can be transmitted by two channels with opposing signs. One of them operates through depreciation of the domestic currency and an increase in net exports. The other channel is through a decrease in foreign aggregated demand, which reduces demand for exports. In our estimated model, the first effect dominates.

\subsubsection{Risk premium shock}

Risk premium shocks exert strong pressure on the nominal exchange rate. Due to the different monetary policy rules, the effects of this type of shock are also different across regimes (Figure 4). As a general statement, the effects of this shock resemble an amplified version of the effects of a contractionary foreign monetary policy shock.

In the crawling peg regime, the immediate effect of an increase in the risk premium is a sharp increase in the interest rates to mitigate the pressure for an exchange rate depreciation. Despite the fact that imported goods inflation is contained, the contractionary effects of policy tightening manifest themselves in the drop of consumption and domestic inflation. As a result of the contraction of domestic absorption and the slight real exchange rate depreciation, net exports increase. However, this result is insufficient to make up for the fall in consumption, and as a result there is a significant drop in GDP.

In the inflation targeting regime, an increase in the risk premium leads to a sharp exchange rate depreciation. As in the crawling peg regime, the real interest rate increases and leads to a drop in consumption. The same occurs with domestic goods inflation. However, these movements are much smaller than in the crawling peg regime. In contrast, imported goods inflation increases much more in the inflation targeting regime. This is due to the strong devaluation of the exchange rate. As a result, net exports increase significantly. The net effect is an increase in GDP.

\subsubsection{Productivity shock}

Finally, we analyze the effects of a positive productivity shock (Figure 5). In this case there is also a marked difference across the two monetary regimes. In both cases, an increase in productivity leads to a drop in domestic goods inflation. However, in the crawling peg regime, the focus in the stability of the nominal exchange rate induces devaluation of the real exchange rate, and stimulates net exports. In the inflation targeting regime, the nominal exchange rate strengthens significantly, despite the larger drop in the interest rate. As a result, imported goods inflation falls, the real exchange rate appreciates, and net exports fall slightly. In summary, an increase in productivity leads to an expansion of economic 

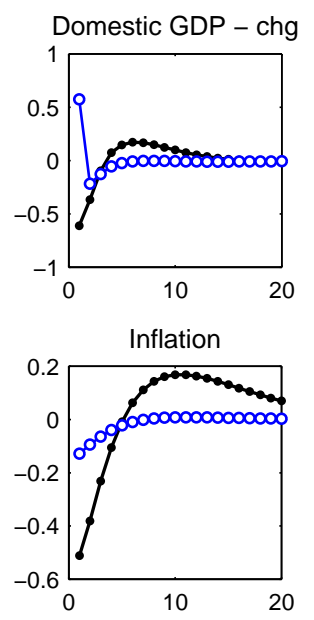

Nominal exchange rate - level

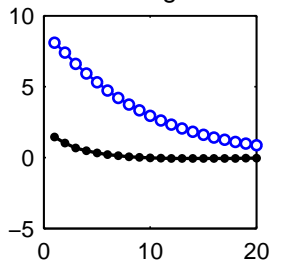

Nominal exchange rate - chg

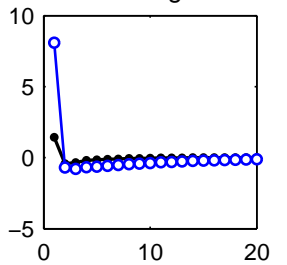

Domestic GDP - level

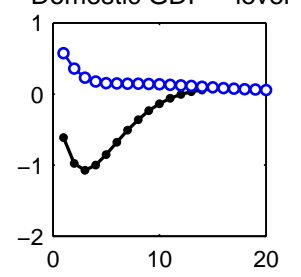

Inflation - domestic goods

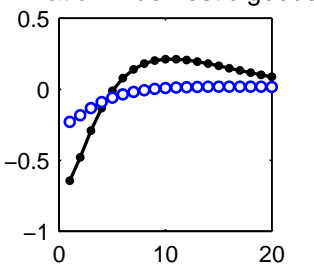

Real exchange rate - level

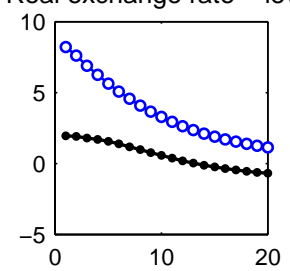

Consumption

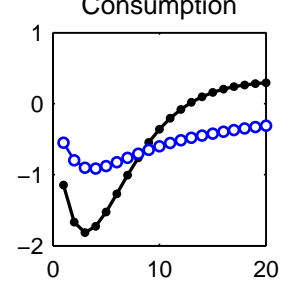

$\longrightarrow$ Crawling peg regime
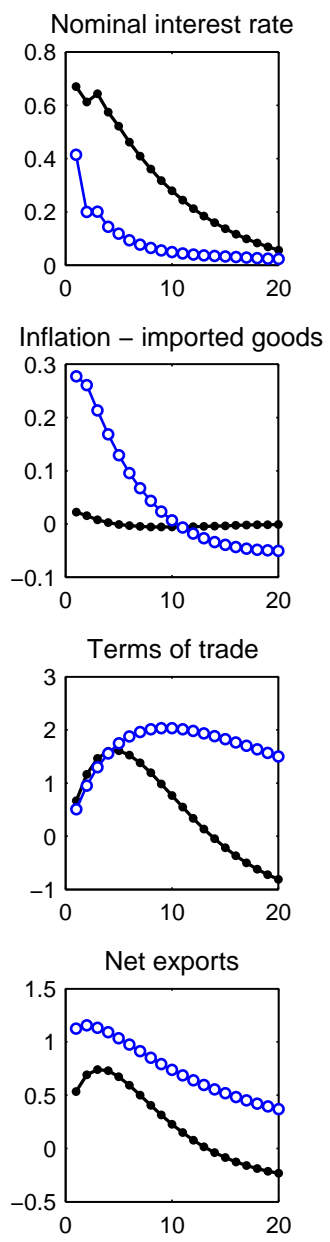

Figure 4: Effects of an increase in the risk premium, in percentage points.

activity in both regimes, but the split between consumption and net exports is different.

\subsubsection{Variance decomposition}

The impulse response functions presented before allow us to visualize the way in which the effects of individual shocks propagate across the two regimes. A variance decomposition exercise allows us to evaluate the relative importance of each shock for aggregate fluctuations in each monetary regime.

In the Appendix we present variance decompositions for a few forecast horizons (Tables 4 and 5). For the sake of brevity, here we focus on a few variables only, and concentrate our analysis on foreign shocks $\left(\epsilon_{y^{*}}, \epsilon_{\pi^{*}}\right.$ and $\left.\epsilon_{i^{*}}\right)$ and on the risk premium shock $\left(\epsilon_{\phi}\right)$.

The foreign monetary policy shock accounts for a larger share of the volatility of the nominal exchange rate in the inflation targeting regime. It is relatively less important in driving movements in domestic GDP, inflation and the interest rate. This is due to the "buffer" role played by the floating exchange 

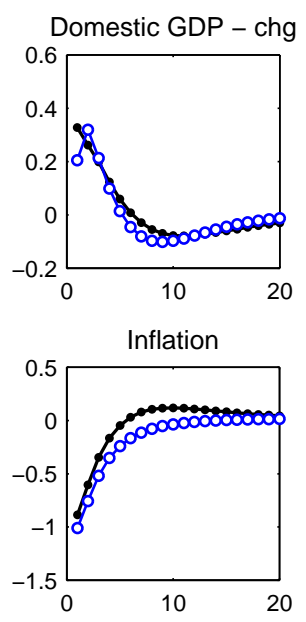

Nominal exchange rate - level

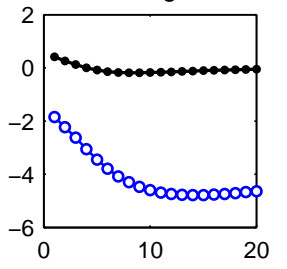

Nominal exchange rate - chg

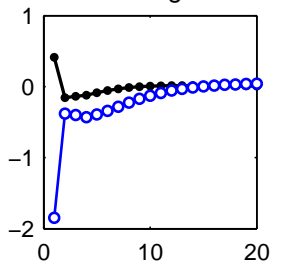

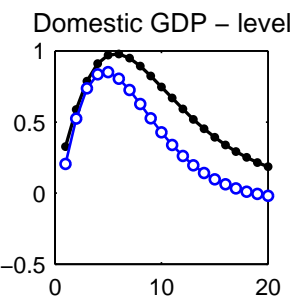

Inflation - domestic goods

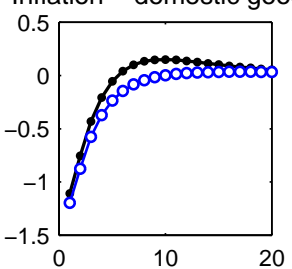

Real exchange rate - level
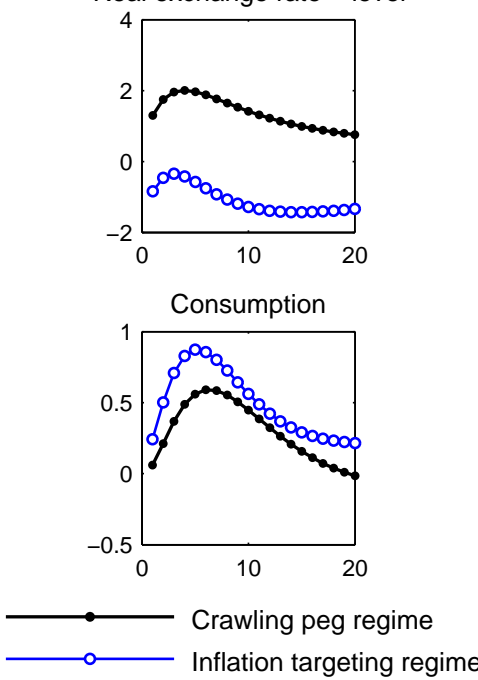

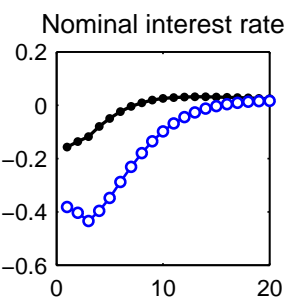

Inflation - imported goods
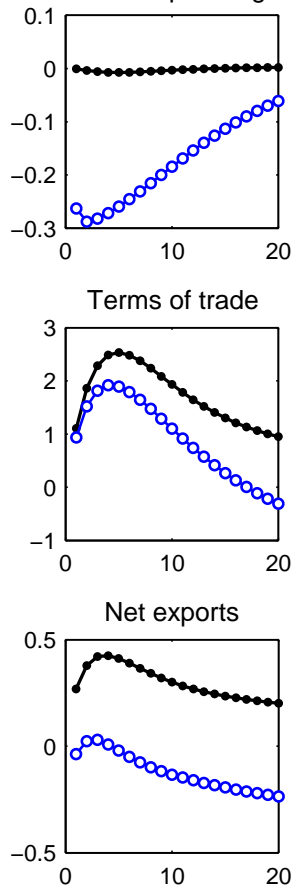

Figure 5: Effects of an increase in productivity, in percentage points.

rate. In the crawling peg regime, the greater relevance of this shock for the behavior of the domestic interest rate illustrates the restrictions placed on monetary policy by the goal of maintaining the nominal exchange rate close to target. The risk premium shock $\epsilon_{\phi}$ is the main driver of the volatility of the nominal exchange rate in both regimes.

Taken jointly, foreign shocks $\epsilon_{y^{*}}, \epsilon_{\pi^{*}}$ and $\epsilon_{i^{*}}$ explain only a modest share of fluctuation in the selected variables. In other words, from the viewpoint of the estimated model, the main sources of fluctuation in the Brazilian economy are associated with domestic factors. This result is in accordance with the findings of Justiniano and Preston (2010) regarding the sources of fluctuations in DSGE models estimated for small open economies, based on models estimated for Australia, Canada, and New Zealand. 


\section{Counterfactual histories}

We use the estimated model to obtain time series of eight structural shocks consistent with the eight macroeconomic series used in the estimation. In order to do so, we use the "Kalman smoother", adjusted for the fact that the model involves a change in the state-space representation, associated with the shift in the monetary regime. This procedure, detailed in the Appendix, recovers not only the time series of structural shocks, but also the series of variables of the model that were not identified with any of the eight time series used in the estimation. We refer to the series of unobserved variables recovered using this procedure as "smoothed series".

Conditional on the estimated model, the smoothed series of the structural shocks should be interpreted as the sequences of innovations that drove fluctuations in the Brazilian economy during the sample period. ${ }^{28}$ With the structural shocks in hand, we can produce a series of counterfactual histories. In particular, we are interested in simulating what would have happened if the transition between monetary regimes had taken place at a time other than the first quarter of 1999.

Each monetary policy regime is associated with a different state-space representation. The counterfactual histories are constructed by feeding the estimated shocks for a given time window using the state-space representation of interest. We can then simulate the path that the economy would have followed under monetary policies other than the one that actually prevailed at that time.

In a model with rational expectations, generating counterfactual histories requires well defined laws of motion for the nominal exchange rate and inflation targets, so that agents can incorporate those in their information set and form expectations accordingly. Therefore, we append to the model stochastic processes that govern the movement of the center of the exchange rate band and the inflation target which were not explicitly included in the estimation of the model (see Section 3.1).

Specifically, we assume that changes in the nominal exchange rate target follow an AR(1) process:

$$
\Delta s_{c, t}=\rho_{s_{c}} \Delta s_{c, t-1}+\sigma_{s_{c}} \epsilon_{s_{c}, t} .
$$

We make the same assumption for the evolution of the inflation target:

$$
\pi_{m, t}=\rho_{\pi_{m}} \pi_{m, t-1}+\sigma_{\pi_{m}} \epsilon_{\pi_{m}, t} .
$$

\footnotetext{
${ }^{28}$ The reader who is not familiar with this type of exercise may find it useful to think of the procedure as being analogous to the recovery of residuals in an ordinary least squares regression (that is, the difference between the data and what the estimated regression would produce in the absence of innovations). The difference is here the procedure requires that we take into account the whole (dynamic) structure of the model. Precisely because of this structure, these recovered shocks ("residuals") have specific economic interpretations - as opposed to residuals produced by purely statistical models. Another issue pertains to the fact that we use a Bayesian framework. We could recover several shock histories, associated with several combinations of structural parameters (whose posterior distribution we estimated). For simplicity and brevity, we chose to select only one vector of structural parameter values as our point estimates (the global mode of the posterior distribution), and recover the associated structural shocks. Hence, despite the Bayesian approach, our strategy for constructing counterfactual histories has a frequentist nature.
} 
The parameters $\rho_{s_{c}}, \sigma_{s_{c}}, \rho_{\pi_{m}}$ and $\sigma_{\pi_{m}}$ can be used to calibrate the desired counterfactual experiments. For our purposes, it is enough to set $\rho_{s_{c}}=\rho_{\pi_{m}}=0.999$ and only calibrate the scale of shocks $\left(\sigma_{s_{c}}\right.$ and $\left.\sigma_{\pi_{m}}\right)$.

With this extension of the estimated model we can simulate, for example, a delay in the adoption of the inflation targeting regime with floating exchange rates. This requires specification of the evolution of the target for the nominal exchange rate past the first quarter of 1999, in a way that allows agents to form (rational) expectations. The addition of the stochastic processes for the nominal exchange rate band and inflation targets to the model fulfills this role.

Figure 6 shows the smoothed structural innovations. One way to assess the plausibility of results is to compare estimates with objective measures of the economic objects of interest that were not used in the estimation. Figure 7 shows the (standardized) series of the risk premium produced by the estimated model and sovereign risk as measured by JP Morgan's EMBI+ Brazil. ${ }^{29}$ The correlation between the two series is 0.89 , which suggests that the estimated model accounts well for the underlying economic environment.
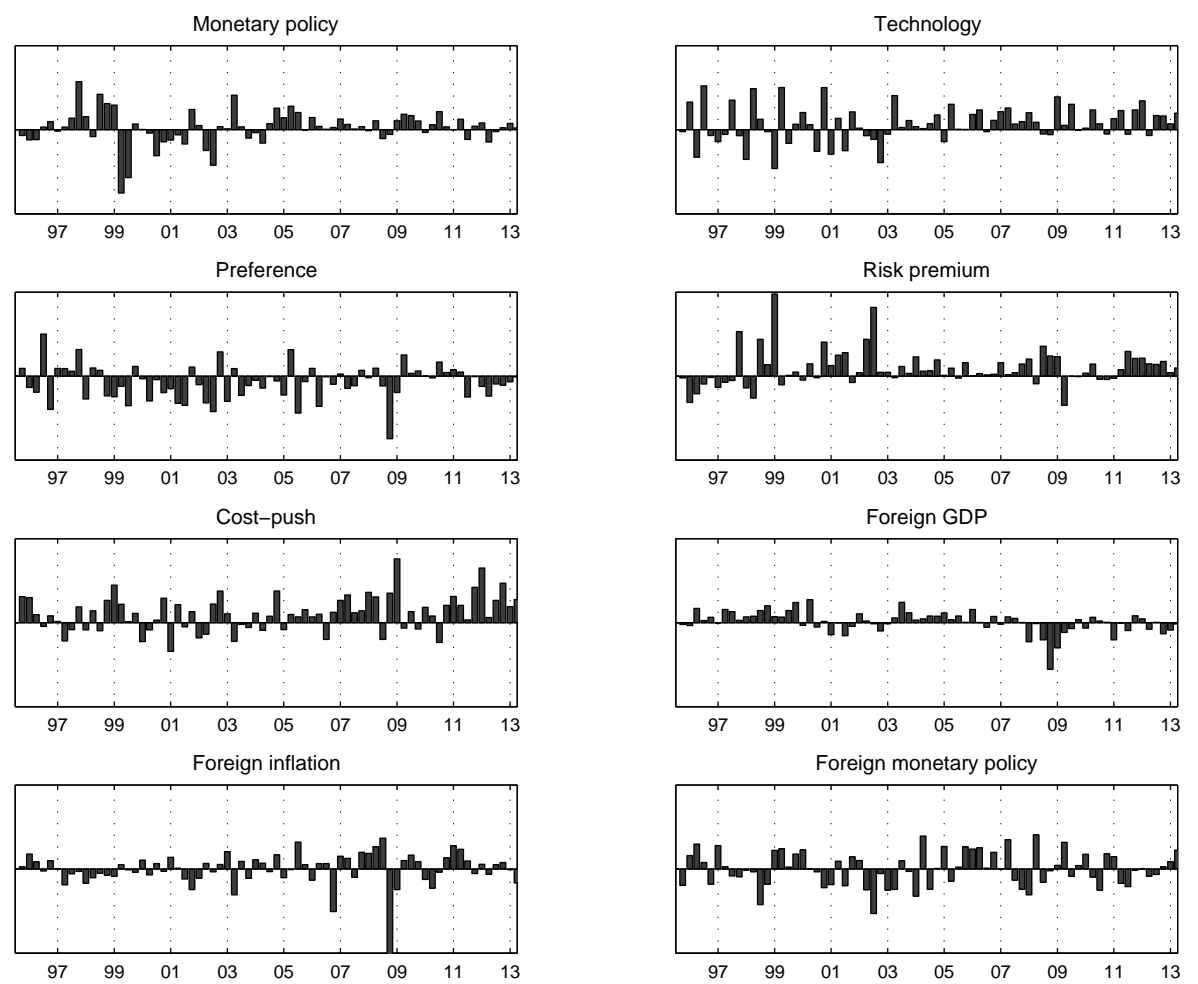

Figure 6: Smoothed structural shocks (innovations)

\footnotetext{
${ }^{29}$ The risk premium is reported in levels (not the innovations), calculated by taking the exponential of the standardized smoothed series. The EMBI+ Brazil series is a quarterly average of daily spreads (source: IPEADATA).
} 


\subsection{Maintaining the crawling peg regime}

What would have happened if the crawling peg regime had not been abandoned in the beginning of 1999? For this simulation, we construct the series using the state-space representation of the crawling peg regime beyond the first quarter of 1999, assuming that the CBB would have kept the rate of devaluation of the nominal exchange target at approximately $7 \%$ per year. This counterfactual history is reported in Figure 8. ${ }^{30}$

Maintaining the crawling peg regime with the same pace of nominal exchange rate devaluation would have required extremely high interest rates for several quarters. GDP would have dropped substantially and remained significantly lower than the trajectory observed during the whole reported horizon (3 years). Finally, inflation in 1999 would have been significantly lower than what was observed.

This exercise leaves aside considerations pertaining to the loss of international reserves that occurred and the effects of high interest rates on public debt dynamics. But even if we take the results of the model literally, this counterfactual exercise favors the view that defending the crawling peg regime would have been too costly.

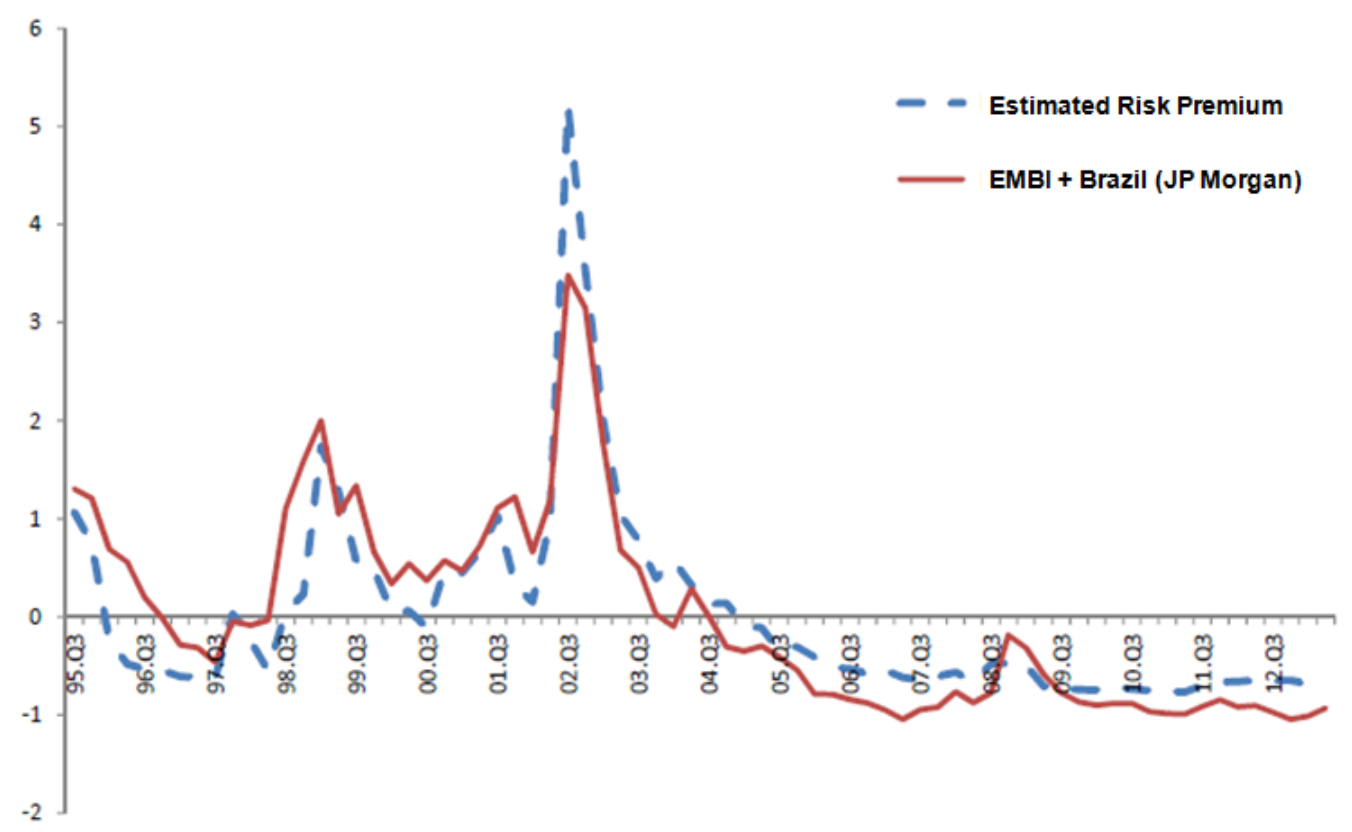

Figure 7: Estimated risk premium and EMBI+Brazil (JP morgan), standardized

\footnotetext{
${ }^{30}$ In all counterfactual histories, we "undo" the transformations applied to the data for estimation purposes, so as to report measures with an immediate interpretation. The nominal interest rate is reported as the annualized quarterly rate, inflation is the percentage change in the aggregate price index over the quarter, the nominal exchange rate is quoted in $\mathrm{R} \$ / \mathrm{US} \$$, and GDP, (smoothed) consumption and the terms of trade are reported as index-numbers.
} 

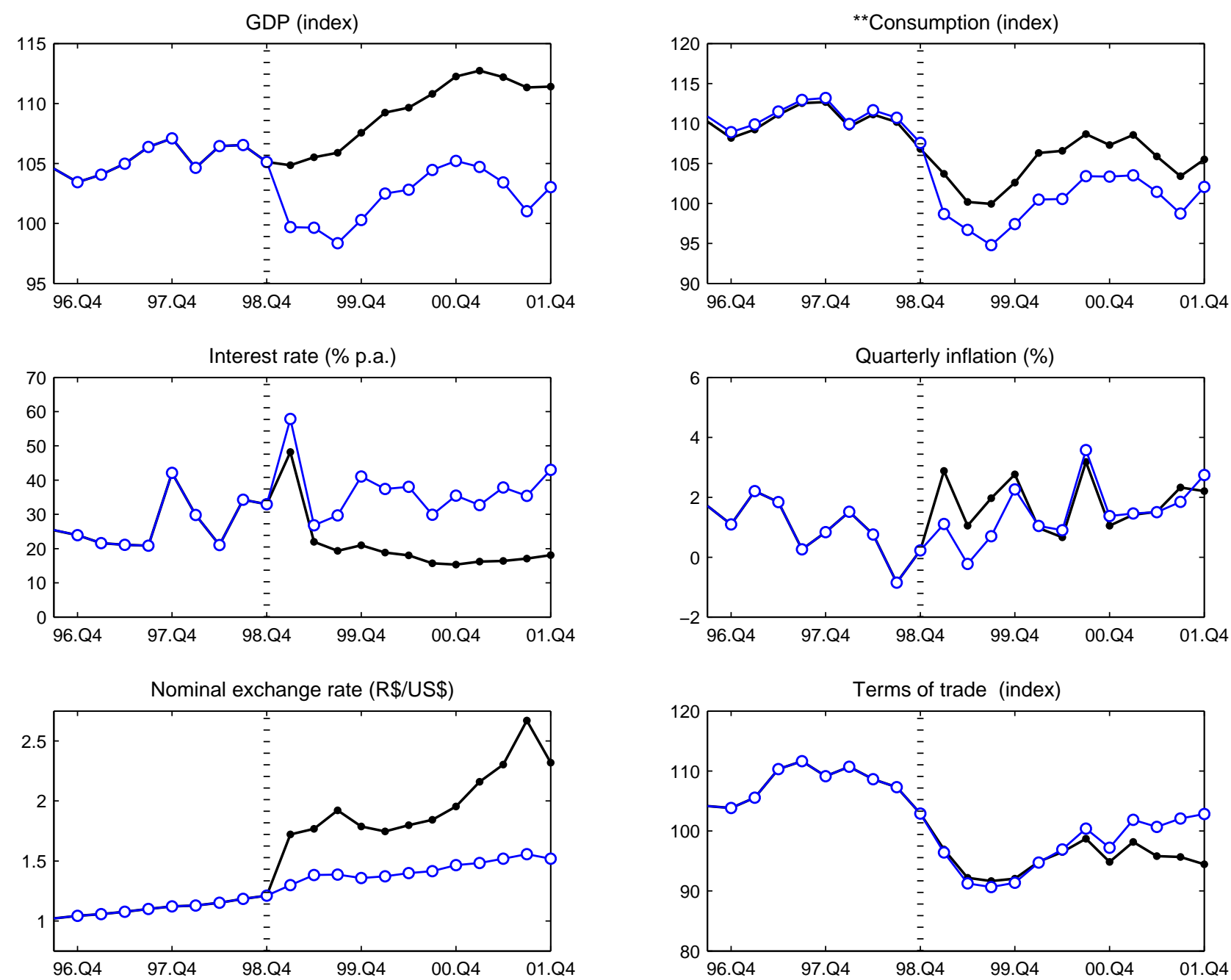

Figure 8: Maintaining the crawling peg regime beyond the first quarter of 1999.

\subsection{Faster devaluation of the exchange rate bands}

Figure 9 simulates the effects of a faster pace of exchange rate devaluation in the crawling peg regime. We assume a pace of devaluation of $14 \%$ p.a., starting after the Asian Crisis (i.e., as of the last quarter of 1997). We keep the switch to inflation targeting in the first quarter of 1999.

Our simulations indicate that this policy would have produced more inflation, higher nominal and real interest rates, and slightly lower economic activity, as the increase in net exports induced by the additional real exchange rate depreciation would prove insufficient to make up for the drop in consumption caused by the increase in the real interest rate. 

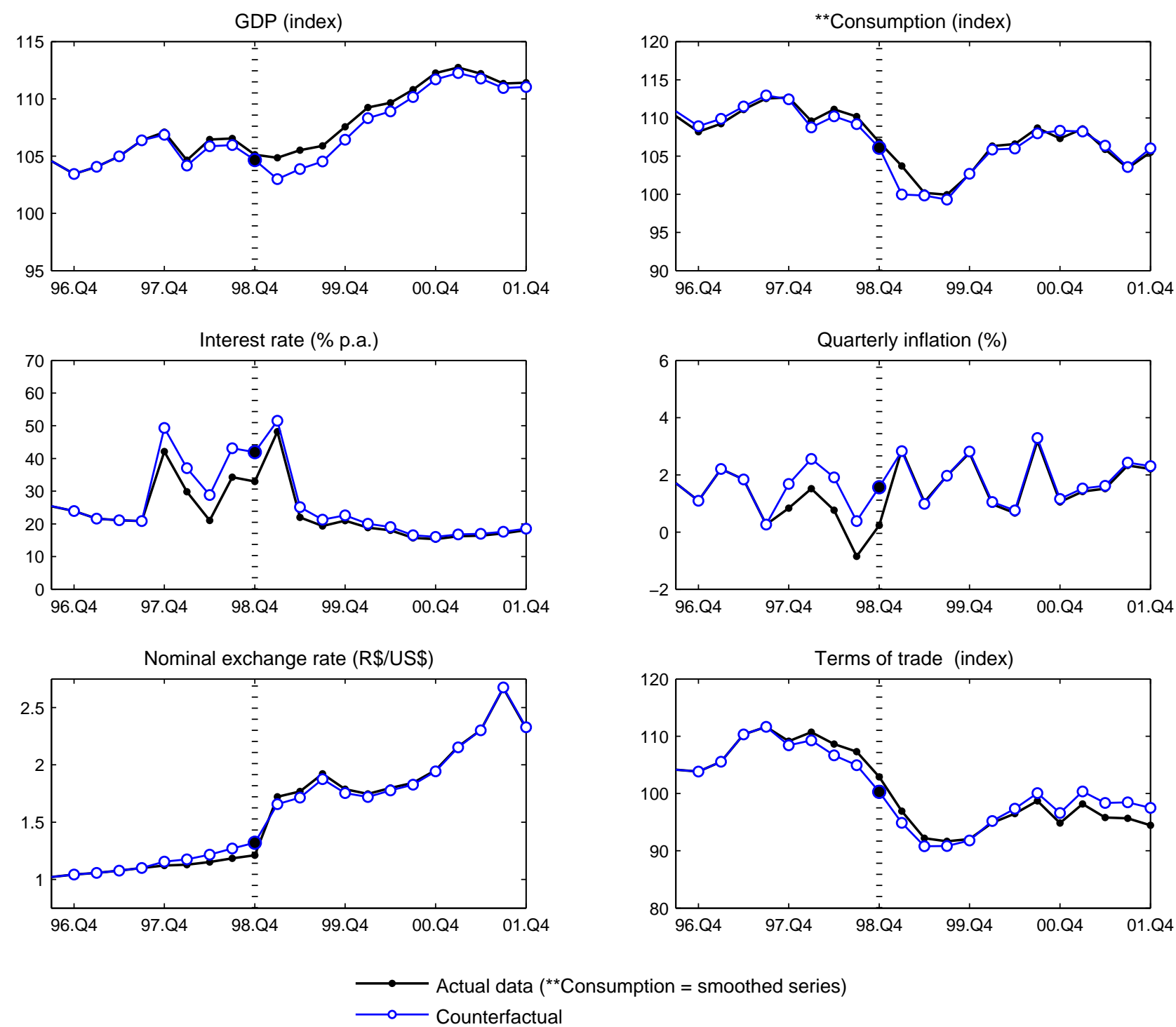

Figure 9: Faster devaluation of exchange rate bands

\subsection{Earlier switch to inflation targeting and floating exchange rates}

Finally, we simulated counterfactual histories in which the transition to the inflation targeting regime and the adoption of a floating exchange rate occurs earlier, in the first or second quarters of 1998. This timing is motivated by the history of risk premium shocks recovered using the estimated model, and by a perception that this would have been a favorable moment for the regime shift. ${ }^{31}$

Figure 10 shows the counterfactual history in which the regime shift takes place in the second quarter of 1998 (results using the first quarter are similar). At that time the transition would have occurred very smoothly, with a slight exchange rate appreciation and small fluctuations in the other macroeconomic variables.

\footnotetext{
${ }^{31}$ See the quote by President Fernando Henrique Cardoso, reproduced in the Introduction of this paper.
} 

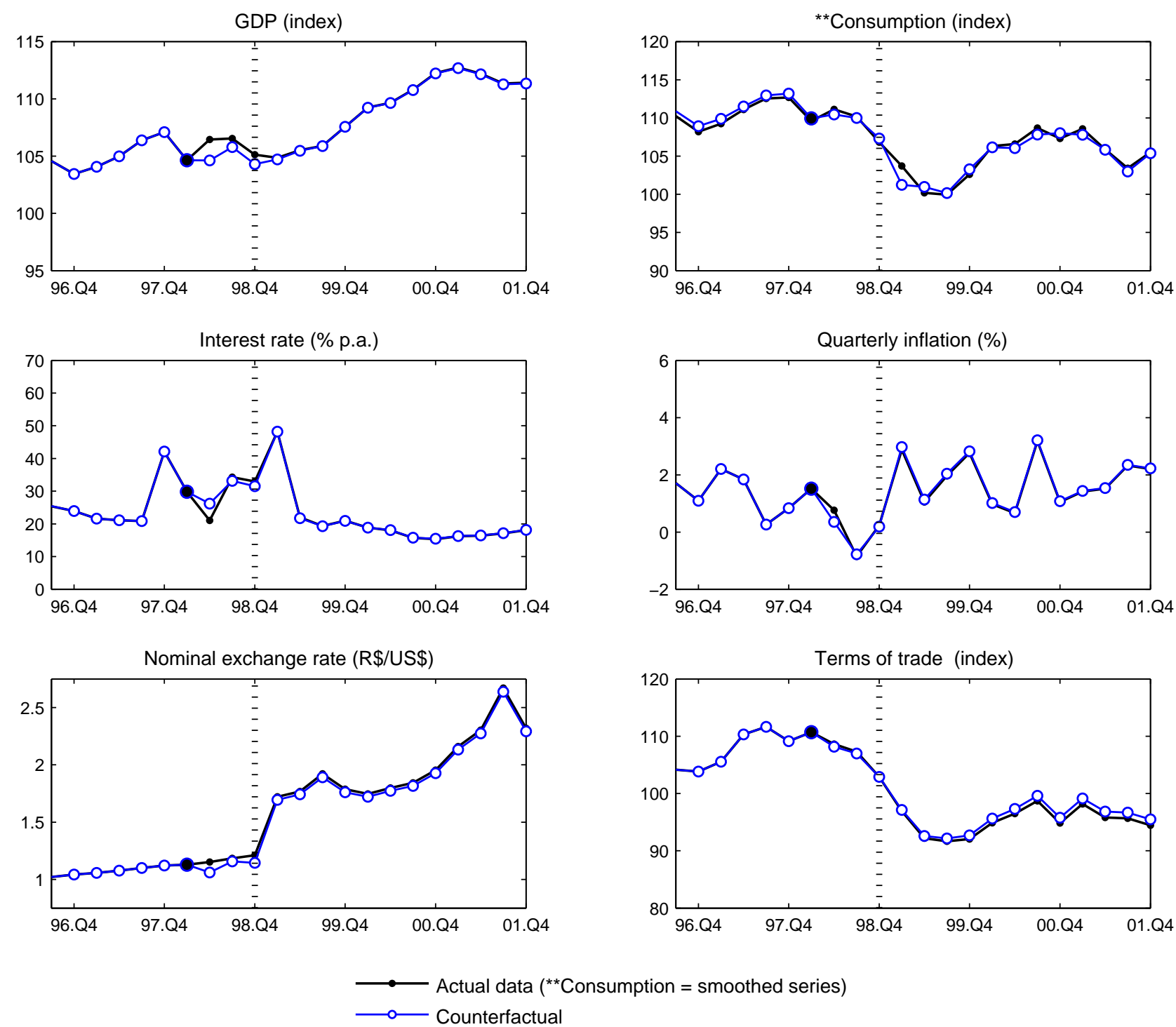

Figure 10: Earlier switch to inflation targeting and floating exchange rates

Notice that, as in the previous experiment, this counterfactual history still features a sharp devaluation of Real in the first quarter of 1999. This is due to the fact that the structural shocks estimated are still acting in the same manner, independently of the monetary/exchange rate regime in place. In particular, the large risk premium shock estimated for that moment continues to exert strong pressure for the devaluation of the exchange rate, which is translated in an actual devaluation in all counterfactual simulations in which the shift to the inflation targeting regime occurs before the first quarter of 1999. 


\section{Conclusion}

The specification of a DSGE model that satisfactorily captures the dynamics of an economy of interest is not a trivial task. This is especially true when dealing with emerging economies, which have a history of vulnerability to foreign factors and recurring periods of macroeconomic instability. In the case of Brazil, all these elements are present, even in the period after the implementation of the Real Plan. This might be the main reason why most of the DSGE models estimated for the Brazilian economy use samples that cover the inflation targeting regime only.

In this paper, we estimate a DSGE model for Brazil using a sample that covers both the crawling peg and the inflation targeting with floating exchange rate regimes. To do so, we explicitly model the associated change in the monetary policy rule. We then compare the dynamics of the estimated model under both regimes. As expected, in the crawling peg regime the model is consistent with a monetary policy focused on keeping the nominal exchange rate on target. This contrasts with the inflation targeting regime, in which the estimated model suggests a focus in the stabilization of inflation around target, and greater policy smoothing. These differences become apparent in the response of the economy to structural shocks.

With the estimated model in hand, we recover the structural shocks that explain the time series of the eight macroeconomic variables used in the estimation. We use them to construct counterfactual histories of the adoption of inflation targeting. Despite the fact that the model abstracts from relevant factors, such as fiscal policy, most counterfactual results seem plausible. In particular, our results suggest that the first semester of 1998 might have offered a window of opportunity for a relatively smooth transition from the crawling peg to the inflation targeting regime with a floating exchange rate.

As we emphasized in more than one occasion, our results are subject to a series of important caveats. The main one, in our opinion, is the fact that the model abstracts from the fiscal dimension. As an example of a possible implication of this simplification, observe that our estimation recovers a series of exogenous risk premium shocks that inevitably exert pressure for the devaluation of the Real in the first quarter of 1999. However, it can be argued that this shock is somewhat endogenous, since the risk premium observed in this and other episodes reflect fiscal sustainability concerns. Additionally, the sharp devaluation in January 1999 was influenced by a loss of international reserves caused by interventions in the foreign exchange market to defend the crawling peg regime, and, for a short period of time, the so-called "endogenous diagonal band". ${ }^{32}$

With relevant modifications to the model, the estimated structural shocks could change significantly.

\footnotetext{
${ }^{32}$ Between abandoning the crawling peg and floating the Real, the CBB tried to implement a new crawling peg regime. The so-called "endogenous diagonal band" would be devalued at a pace that would depend on the behavior of the nominal exchange rate within the band. More specifically, the pace of devaluation would be faster when the exchange rate was closer to the bottom end of the band (i.e., stronger), and slower when the exchange rate was closer to the upper end of the band (i.e., weaker). This exchange rate arrangement lasted for two days.
} 
As a result, it is possible that the counterfactual simulations would come out different. For example, with a model that relates the risk premium to fiscal policy, it is possible that the estimated exogenous shocks would change substantially and that the "inevitable devaluation" in the first quarter of 1999 would disappear. This is an interesting question for future research. 


\section{References}

An, S. and F. Schorfheide (2007). Bayesian Analysis of DSGE Models. Econometric Rewiews 26(2-4), $113-172$.

Bernanke, B., J. Boivin, and P. Eliasz (2005). Measuring the Effects of Monetary Policy: A Factoraugmented Vector Autoregressive (FAVAR) Approach. The Quarterly Journal of Economics 120(1), 387.

Berriel, T., C. Carvalho, and R. Ihara (2013). Que Regime Monetário-cambial?, in Fábio Giambiagi and Cláudio Porto (orgs): Propostas para o governo 2015-2018 - Agenda para um país prospero e competitivo. Elsevier.

Calvo, G. A. (1983). Staggered Prices in a Utility-maximizing Framework. Journal of Monetary Economics 12(3), 383-398.

Cardoso, F. H. (2006). Arte da Política: A História que Vivi. Record.

Carvalho, C., F. Cordeiro, and J. Vargas (2013). Just Words?: A Quantitative Analysis of the Communication of the Central Bank of Brazil. Revista Brasileira de Economia 67(4), 443-455.

Carvalho, C. and A. D. Vilela (2015). E Se o Brasil Não Tivesse Adotado Câmbio Flutuante em 1999? Texto para Discussão 645, Departamento de Economia da PUC-Rio.

Cúrdia, V. and D. Finocchiaro (2013). Monetary Regime Change and Business Cycles. Journal of Economic Dynamics and Control 37(4), 756-773.

Davig, T. and E. Leeper (2010). Generalizing the Taylor Principle. American Economic Review 97(3), $618-624$.

de Castro, M., S. Gouvea, A. Minella, R. Santos, and N. Sobrinho (2011). SAMBA: Stochastic Analytical Model with a Bayesian Approach. Working Paper Series 239, Banco Central do Brasil.

Del Negro, M. and F. Schorfheide (2009). Inflation Dynamics in a Small Open-economy Model under Inflation Targeting: Some evidence from Chile. Monetary Policy Under Uncertainty and Learning 13, $511-562$.

Fernandez-Villaverde, J. (2010). The Econometrics of DSGE Models. Journal of the Spanish Economic Association 1(1), 3-49.

Friedman, M. (1966). Essays in Positive Economics. University of Chicago Press. 
Galí, J. and T. Monacelli (2005). Monetary Policy and Exchange Rate Volatility in a Small Open Economy. Review of Economic Studies 72(3), 707-734.

Gonçalves, C. E. (2015). Too Tight and Too Loose: Monetary Policy in Brazil in the Last Decade. Mimeo.

Guerron-Quintana, P. A. and J. M. Nason (2013). Bayesian Estimation of DSGE Models. Handbook of Empirical Methods in Macroeconomics, 486-512.

Guiso, L., P. Sapienza, and L. Zingales (2013). Time Varying Risk Aversion. NBER Working Paper 19284.

Hamilton, J. D. (2004). Time Series Analysis. Princeton University Press.

Justiniano, A. and B. Preston (2010). Monetary Policy and Uncertainty in an Empirical Small Openeconomy Model. Journal of Applied Econometrics 25(1), 93-128.

Monacelli, T. (2004). Into the Mussa Puzzle: Monetary Policy Regimes and the Real Exchange Rate in a Small Open Economy. Journal of International Economics (62), 191-217.

Schmitt-Grohe, S. and M. Uribe (2003). Closing Small Open Economy Models. Journal of International Economics 61, 163-185.

Sims, C. (2002). Solving Linear Rational Expectations Models. Journal of Computational Economics 20(1-2), 1-20.

Swanson, E. T. and J. C. Williams (2014). Measuring the Effect of the Zero Lower Bound on Mediumand Longer-Term Interest Rates. American Economic Review 104(10), 3154-85.

Vilela, A. D. (2014). De Câmbio Fixo a Metas para a Inflação: Mudança Estrutural de Política Monetária em um Modelo DSGE Estimado para a Economia Brasileira. Dissertação de Mestrado, Departamento de Economia da PUC-Rio.

Woodford, M. (2003). Interest and Prices. Princeton University Press. 


\section{A Appendix}

\section{A.1 First-order approximation of the model}

For the estimation of the model we use a (log-)linear approximation of the equilibrium around a non-

stochastic stationary state. ${ }^{33}$ The steady state of the model is characterized by zero inflation, balanced commerce and absence of foreign debt.

The full set of log-linearized equations used in the estimation of the model is:

- Euler equation

$$
c_{t}-h c_{t-1}=E_{t}\left(c_{t+1}-h c_{t}\right)-\frac{1-h}{\sigma}\left(i_{t}-E_{t} \pi_{t+1}\right)+\frac{1-h}{\sigma}\left(\gamma_{t}-E_{t} \gamma_{t+1}\right) .
$$

- Goods market equilibrium

$$
y_{t}=(1-\alpha) c_{t}+\alpha \eta(2-\alpha) \operatorname{tot}_{t}+\alpha \eta \psi_{I, t}+\alpha y_{t}^{*}
$$

- Terms of trade

$$
\Delta \text { tot }_{t}=\pi_{I, t}-\pi_{D, t} .
$$

- Relationship between the real exchange rate and terms of trade:

$$
q_{t}=\psi_{I, t}+(1-\alpha) \text { tot }_{t}
$$

- Relationship between the nominal and real exchange rates

$$
q_{t}=q_{t-1}+s_{t}-s_{t-1}+\pi_{t}^{*}-\pi_{t}
$$

- Phillips Curve: Domestic producers

$$
\pi_{D, t}-\delta_{D} \pi_{D, t-1}=\beta E_{t}\left(\pi_{D, t+1}-\delta_{D} \pi_{D, t}\right) \frac{\left(1-\theta_{D}\right)\left(1-\theta_{D} \beta\right)}{\theta_{D}} m c_{D, t},
$$

where:

$$
m c_{D, t}=\alpha t o t_{t}+\varphi y_{t}+\sigma(1-h)^{-1}\left(c_{t}-h c_{t-1}\right)-(1+\varphi) a_{t} .
$$

- Phillips Curve: Importing firms

$$
\pi_{I, t}-\delta_{I} \pi_{I, t-1}=\beta E_{t}\left(\pi_{I, t+1}-\delta_{I} \pi_{I, t}\right)+\frac{\left(1-\theta_{I}\right)\left(1-\theta_{I} \beta\right)}{\theta_{I}} \psi_{I, t}+\varepsilon_{c p, t}
$$

\footnotetext{
${ }^{33}$ For details on the equations that characterize the equilibrium of the original non-linear model and the first-order approximation, see Carvalho and Vilela (2015) and Vilela (2014).
} 
- Relationship between inflation and terms of trade

$$
\pi_{t}=\pi_{D, t}+\alpha \Delta \text { tot }_{t}
$$

- Budget constraint

$$
a_{t}=\beta^{-1} a_{t-1}-\alpha\left(s_{t}+\psi_{I, t}\right)+y_{t}-c_{t} .
$$

- Uncovered interest rate parity

$$
i_{t}=i_{t}^{*}+E_{t} s_{t+1}-s_{t}-\chi z_{t}+\phi_{t} .
$$

- Monetary policy rules

- Crawling peg regime

$$
i_{t}=\rho_{i, 1}^{F X} i_{t-1}+\rho_{i, 2}^{F X} i_{t-2}+\left(1-\rho_{i, 1}^{F X}-\rho_{i, 2}^{F X}\right)\left(\lambda_{\pi}^{F X} \pi_{t}+\lambda_{y}^{F X} y_{t}+\lambda_{s}^{F X} s_{x, t}\right)+\varepsilon_{i, t}^{F X} .
$$

- Inflation targeting regime

$$
i_{t}=\rho_{i, 1}^{I T} i_{t-1}+\rho_{i, 2}^{I T} i_{t-2}+\left(1-\rho_{i, 1}^{I T}-\rho_{i, 2}^{I T}\right)\left(\lambda_{\pi}^{I T} \pi_{t}+\lambda_{y}^{I T} y_{t}+\lambda_{s}^{I T} \Delta s_{t}\right)+\varepsilon_{i, t}^{I T} .
$$

- Foreign block

$$
\begin{gathered}
A_{0}\left[\begin{array}{c}
Y_{t}^{*} \\
\pi_{t}^{*} \\
i_{t}^{*}
\end{array}\right]=A_{1}\left[\begin{array}{c}
Y_{t-1}^{*} \\
\pi_{t-1}^{*} \\
i_{t-1}^{*}
\end{array}\right]+\left[\begin{array}{c}
\varepsilon_{y}^{*} \\
\varepsilon_{\pi}^{*} \\
\varepsilon_{i}^{*}
\end{array}\right] \\
A_{0}=\left[\begin{array}{ccc}
1 & 0 & 0 \\
a_{0, \pi y} & 1 & 0 \\
a_{0, i y} & a_{0, i \pi} & 1
\end{array}\right] \quad A_{1}=\left[\begin{array}{lll}
a_{1, y y} & a_{1, y \pi} & a_{1, y i} \\
a_{1, \pi y} & a_{1, \pi \pi} & a_{1, \pi i} \\
a_{1, i y} & a_{1, i \pi} & a_{1, i i}
\end{array}\right] .
\end{gathered}
$$

- Structural shocks

$$
\begin{gathered}
a_{t}=\rho_{a} a_{t-1}+\sigma_{a} \epsilon_{a, t}, \\
\gamma_{t}=\rho_{\gamma} \gamma_{t-1}+\sigma_{\gamma} \epsilon_{\gamma, t}, \\
\varepsilon_{c p, t}=\rho_{c p} \varepsilon_{c p, t-1}+\sigma_{c p} \epsilon_{c p, t}, \\
\phi_{t}=\rho_{\phi} \phi_{t-1}+\sigma_{\phi} \epsilon_{\phi, t}, \\
\varepsilon_{i, t}^{r}=\sigma_{i, r} \epsilon_{i, t}, \quad r=F X, I T, \\
\varepsilon_{y^{*}, t}=\sigma_{y^{*}} \epsilon_{y^{*}, t}, \quad \varepsilon_{\pi^{*}, t}=\sigma_{\pi^{*}} \epsilon_{\pi^{*}, t}, \quad \varepsilon_{i^{*}, t}=\sigma_{i^{*}} \epsilon_{i^{*}, t} .
\end{gathered}
$$

The $\epsilon$ innovations are i.i.d. $N(0,1)$ and mutually independent. 


\section{A.2 Details of the estimation}

We estimate the model using Bayesian methods. The main steps of the estimation are briefly discussed below. An and Schorfheide (2007), Fernandez-Villaverde (2010) and Guerron-Quintana and Nason (2013) provide a detailed exposition of these methods and an encompassing survey of developments in this area.

The goal of the Bayesian estimation is to characterize the posterior distribution $P\left(\theta \mid\left\{\Upsilon^{o b s}\right\}_{t}^{T}\right)$ of the DSGE model parameters $\theta$ conditional on the observed sample $\left\{\Upsilon^{o b s}\right\}_{t}^{T}$. To that end, we exploit the fact that the posterior distribution is proportional to the likelihood function of the DSGE model $L\left(\left\{\Upsilon^{o b s}\right\}_{t}^{T} \mid \theta\right)$, multiplied by the prior distribution $P(\theta)$ of the parameters:

$$
P\left(\theta \mid\left\{\Upsilon^{o b s}\right\}_{t}^{T}\right) \propto L\left(\left\{\Upsilon^{o b s}\right\}_{t}^{T} \mid \theta\right) \times P(\theta)
$$

By applying the Kalman filter to the state-space representation of the model, it is possible to calculate the likelihood function, which, combined with the prior distribution, allows the evaluation of the value of the posterior density function (up to a constant of proportionality).

Using numeric optimization methods, ${ }^{34}$ we obtain an approximate estimate of the mode of the posterior distribution of the structural parameters. We then use this estimate as a starting point for the RW-MH-MCMC (Randon Walk Metropolis Hastings-Markov Chain Monte Carlo) algorithm, obtaining a simulated sample of the posterior distribution ${ }^{35}$

Point estimates for the parameters gathered in $\theta$ can be obtained based on central tendency statistics such as mean and median of the posterior distribution, or its global mode. Similarly, measures of uncertainty about the structural parameters can be obtained by computing the standard deviation or probability intervals based on the sample of the posterior distribution obtained by simulation.

\section{A.2.1 Kalman filter with change in regime}

To incorporate the change in regime in the estimation we use the approach proposed by Cúrdia and Finocchiaro (2013). The starting point is to rewrite the posterior distribution, explicitly considering the sub-samples of each monetary policy regime:

$$
P\left(\theta \mid\left\{\Upsilon^{o b s}\right\}_{t}^{T}\right) \propto L\left(\Upsilon_{t \in F X}^{o b s} \mid \theta\right) \times L\left(\Upsilon_{t \in I T}^{o b s} \mid \theta\right) \times P(\theta)
$$

where $L\left(Y_{t \in F X}^{\text {Tobs }} \mid \theta\right)$ and $L\left(Y_{t \in I T}^{\text {Tobs }} \mid \theta\right)$ correspond to the likelihood functions of the data (given $\theta$ ) for the sample periods corresponding to the crawling peg and inflation targeting regimes, respectively, obtained with the Kalman filter.

\footnotetext{
${ }^{34}$ We used the optimization algorithm csminwel.m created by Chris Sims, available at http://sims.princeton.edu/yftp/optimize.

${ }^{35}$ We used three chains of 200.000 observations to carry out convergence tests of the simulation.
} 
We start the recursive procedure by applying the Kalman filter to the state-space representation corresponding to the crawling peg regime, reproduced below:

$$
\begin{gathered}
\Upsilon_{t}=A^{F X}(\theta) \Upsilon_{t-1}+B^{F X}(\theta) \epsilon_{t} \\
\Upsilon_{t}^{o b s}=C \Upsilon_{t} .
\end{gathered}
$$

Given the assumption of normality of exogenous shocks $\epsilon_{t}$, for each time period we have:

$$
\Upsilon_{t}^{o b s} \mid\left\{\Upsilon_{j}^{o b s}\right\}_{j=1}^{t-1} \sim N\left(\mu_{t}(\theta), \Sigma_{t}(\theta)\right)
$$

where $\mu_{t}(\theta)$ and $\Sigma_{t}(\theta)$ are, respectively, the mean and conditional variance of $\Upsilon_{t}^{o b s}$, calculated using the Kalman filter.

The procedure begins with the attribution of initial conditions for the state vector $\Upsilon_{t}$. For the mean $\Upsilon_{0 \mid 0}$, we use a vector of zeros. For the variance $\mathcal{P}_{0 \mid 0}$, we use the unconditional variance of $\Upsilon_{t}$. We then iterate the recursion of the Kalman filter forward, until the last period of the crawling peg regime. Formally:

$$
\begin{gathered}
\Upsilon_{t \mid t-1}=A^{F X} \Upsilon_{t-1 \mid t-1} \\
\mathcal{P}_{t \mid t-1}=A^{F X} \mathcal{P}_{t-1 \mid t-1}\left(A^{F X}\right)^{\prime}+B^{F X}\left(B^{F X}\right)^{\prime} \\
K_{t}=\mathcal{P}_{t \mid t-1} C^{\prime}\left(C \mathcal{P}_{t \mid t-1} C^{\prime}\right)^{-1} \\
\Upsilon_{t \mid t}=\Upsilon_{t \mid t-1}+K_{t} u_{t} \\
\mathcal{P}_{t \mid t}=\left(I-K_{t} C\right) \mathcal{P}_{t \mid t-1},
\end{gathered}
$$

where $u_{t}$ are the one-step-ahead prediction errors:

$$
u_{t}=\Upsilon_{t}^{o b s}-C \Upsilon_{t \mid t-1}
$$

In each period, we compute the forecast error and the log-likelihood function according to:

$$
l_{t}=-\frac{T}{2} \ln (2 \pi)-\ln \left|\Sigma_{u, t}^{-1}\right|+u_{t}^{\prime} \Sigma_{u, t} u_{t},
$$

where:

$$
\Sigma_{u, t}=u_{t} u_{t}^{\prime}
$$

At the end of the recursion, we calculate the log-likelihood of the sub-sample corresponding to the crawling peg regime:

$$
\mathcal{L}^{F X}=\sum_{t \in F X} l_{t}
$$


In the transition to the sample period which corresponds to the inflation targeting regime, the initial state of the economy used in the recursion corresponds to the last state in the crawling peg regime. Thus, for the mean we use the state vector of the last period of the crawling peg regime and for the variance we used the associated $\mathcal{P}_{t}$ matrix.

With the initial state defined, we can proceed recursively, in a manner that is analogous to what we did for the crawling peg regime, but using the space-state representation associated with the inflation targeting regime. Therefore, from this period forward, we have:

$$
\begin{gathered}
\Upsilon_{t \mid t-1}=A^{I T} \Upsilon_{t-1 \mid t-1} \\
\mathcal{P}_{t \mid t-1}=A^{I T} \mathcal{P}_{t-1 \mid t-1}\left(A^{I T}\right)^{\prime}+B^{I T}\left(B^{I T}\right)^{\prime} \\
K_{t}=\mathcal{P}_{t \mid t-1} C^{\prime}\left(C \mathcal{P}_{t \mid t-1} C^{\prime}\right)^{-1} \\
\Upsilon_{t \mid t}=\Upsilon_{t \mid t-1}+K_{t} u_{t} \\
\mathcal{P}_{t \mid t}=\left(I-K_{t} C\right) \mathcal{P}_{t \mid t-1} .
\end{gathered}
$$

Finally, at the end of the recursion we compute the log-likelihood of the sub-sample corresponding to the inflation targeting regime, obtained in an analogous manner to that described for the previous regime:

$$
\mathcal{L}^{I T}=\sum_{t \in I T} l_{t}
$$

\section{A.2.2 Prior distribution}

A detailed desciption of the choice of priors for the structural parameters can be found in Carvalho and Vilela (2015). For brevity, here we only summarize those choices in Table 3. However, for completeness, we comment on parameters that are calibrated.

Following de Castro et al. (2011), the time-discount factor $(\beta)$ is set to $0.989 .{ }^{36}$ The (Frisch) elasticity of labor supply $\left(\varphi^{-1}\right)$ is set to 1.0. Finally, the parameter $\alpha$, which can be interpreted as the degree of openness of the economy, is set to 0.25 , corresponding to the ratio between gross trade flows and GDP over the sample period. ${ }^{37}$

\footnotetext{
${ }^{36}$ Here there should be a restriction relating $\beta$ with foreign interest rate and inflation in the steady state (see Carvalho and Vilela (2015), Section A.1.3). However, we decided not to impose this restriction, estimate the foreign block separately, and calibrate the time-discount factor in conformity with the SAMBA model.

${ }^{37}$ The elasticity of substitution between varieties $(\varepsilon)$ does not show up in the log-linear approximation of the model, and hence it does not affect its estimation.
} 
Table 3: Marginal prior and posterior distributions of parameters.

\begin{tabular}{|c|c|c|c|c|c|}
\hline \multirow[b]{2}{*}{ Parameter } & \multicolumn{3}{|c|}{ Details of the prior distribution } & \multicolumn{2}{|c|}{ Posterior distribution } \\
\hline & $\begin{array}{l}\text { Parametric } \\
\text { family }\end{array}$ & Mode & $\mathrm{SD}$ & Mode** & $\mathrm{SD}$ \\
\hline$h$ & Beta & 0.85 & 0.05 & 0.68 & 0.05 \\
\hline$\sigma$ & Gama & 1.30 & 0.05 & 1.27 & 0.05 \\
\hline$\eta$ & Gama & 1.00 & 0.50 & 0.58 & 0.03 \\
\hline$\delta_{D}$ & Beta & 0.65 & 0.20 & 0.07 & 0.06 \\
\hline$\theta_{D}$ & Beta & 0.65 & 0.10 & 0.82 & 0.02 \\
\hline$\delta_{I}$ & Beta & 0.65 & 0.20 & 0.13 & 0.08 \\
\hline$\theta_{I}$ & Beta & 0.65 & 0.10 & 0.92 & 0.01 \\
\hline$\chi$ & Gama & 0.02 & 0.01 & 0.02 & 0.01 \\
\hline$\rho_{a}$ & Beta & 0.50 & 0.25 & 0.79 & 0.10 \\
\hline$\rho_{\gamma}$ & Beta & 0.50 & 0.25 & 0.60 & 0.10 \\
\hline$\rho_{c p}$ & Beta & 0.50 & 0.25 & 0.12 & 0.11 \\
\hline$\rho_{\phi}$ & Beta & 0.50 & 0.25 & 0.88 & 0.02 \\
\hline$\sigma_{a}$ & Gama Inv & 1.00 & 0.75 & 5.57 & 1.64 \\
\hline$\sigma_{\gamma}$ & Gama Inv & 1.00 & 0.75 & 10.34 & 1.79 \\
\hline$\sigma_{c p}$ & Gama Inv & 1.00 & 0.75 & 2.08 & 0.27 \\
\hline$\sigma_{\phi}$ & Gama Inv & 1.00 & 0.75 & 1.10 & 0.17 \\
\hline$\rho_{i, 1}^{F X}$ & Beta & 0.60 & 0.15 & 0.31 & 0.10 \\
\hline$\rho_{i, 2}^{F X}$ & Beta & 0.60 & 0.15 & 0.33 & 0.10 \\
\hline$\lambda_{\pi}^{F X}$ & Gama & 2.00 & 0.50 & 1.52 & 0.35 \\
\hline$\lambda_{y}^{F X}$ & Gama & 0.25 & 0.10 & 0.28 & 0.10 \\
\hline$\lambda_{s}^{F X}$ & Gama & 1.50 & 0.50 & 1.96 & 0.47 \\
\hline$\sigma_{i}^{F X}$ & Gama Inv & 1.00 & 0.75 & 1.73 & 0.34 \\
\hline$\rho_{i, 1}^{I T}$ & Beta & 0.60 & 0.15 & 0.54 & 0.08 \\
\hline$\rho_{i, 2}^{I T}$ & Beta & 0.60 & 0.15 & 0.30 & 0.08 \\
\hline$\lambda_{\pi}^{I T}$ & Gama & 2.00 & 0.50 & 1.99 & 0.41 \\
\hline$\lambda_{y}^{I T}$ & Gama & 0.25 & 0.10 & 0.70 & 0.15 \\
\hline$\lambda_{\Delta s}^{I T}$ & Gama & 1.50 & 0.50 & 0.31 & 0.09 \\
\hline$\sigma_{i}^{I T}$ & Gama Inv & 1.00 & 0.75 & 0.79 & 0.09 \\
\hline
\end{tabular}

Obs: ** Global mode of the joint posterior distribution. 


\section{A.2.3 Estimation: A few additional results}

Table 3 (above) reports the mode and standard deviation for structural parameters, based on the global mode of the posterior distribution. We first present the invariant parameters, and then the parameters of the monetary policy rule of each regime. A comparison between prio and posterior distributiosn of the parameters of the monetary policy rules can also be seen in Figures 11 e 12.

\section{A.2.4 Variance decompositions}

Tables 4 e 5 present the variance decompositions for the 1, 4 and 20 quarter horizons. Each line reports the relative contribution of the shocks indicated in each column for the variance of the various variables.

\section{A.3 Details of the procedure to recover structural shocks}

To recover the shocks that, according to the model, affected the Brazilian economy in the sample period, we start with the Kalman smoothing algorithm. Given the sample used in the estimation, this algorithm iterates the dynamic of the state-space representation of the model estimated and recovers shocks which, when propagated through the system, reproduce the observed time series. For this procedure, we attribute to each structural parameter of the model its value at the global mode of the posterior distribution.

Due to the change in monetary regime, the use of the standard Kalman smoother does not correctly recover the structural shocks in our model. This happens because the standard algorithm assumes a single state-space representation for the entire sample. To solve this problem, we use the shocks recovered with the standard smoother as initial estimates of the true structural shocks. We then use these estimates as initial guesses for an optimization algorithm, used to minimize the distance between the series simulated by propagating the shocks through the model and the observed data. ${ }^{38}$

\footnotetext{
${ }^{38}$ The minimization procedure is able to drive this distance to zero, thus recovering the sequence of structural shocks which, when propagated through the estimated model, produce series that are equal to the eight macroeconomic time series used in the estimation.
} 

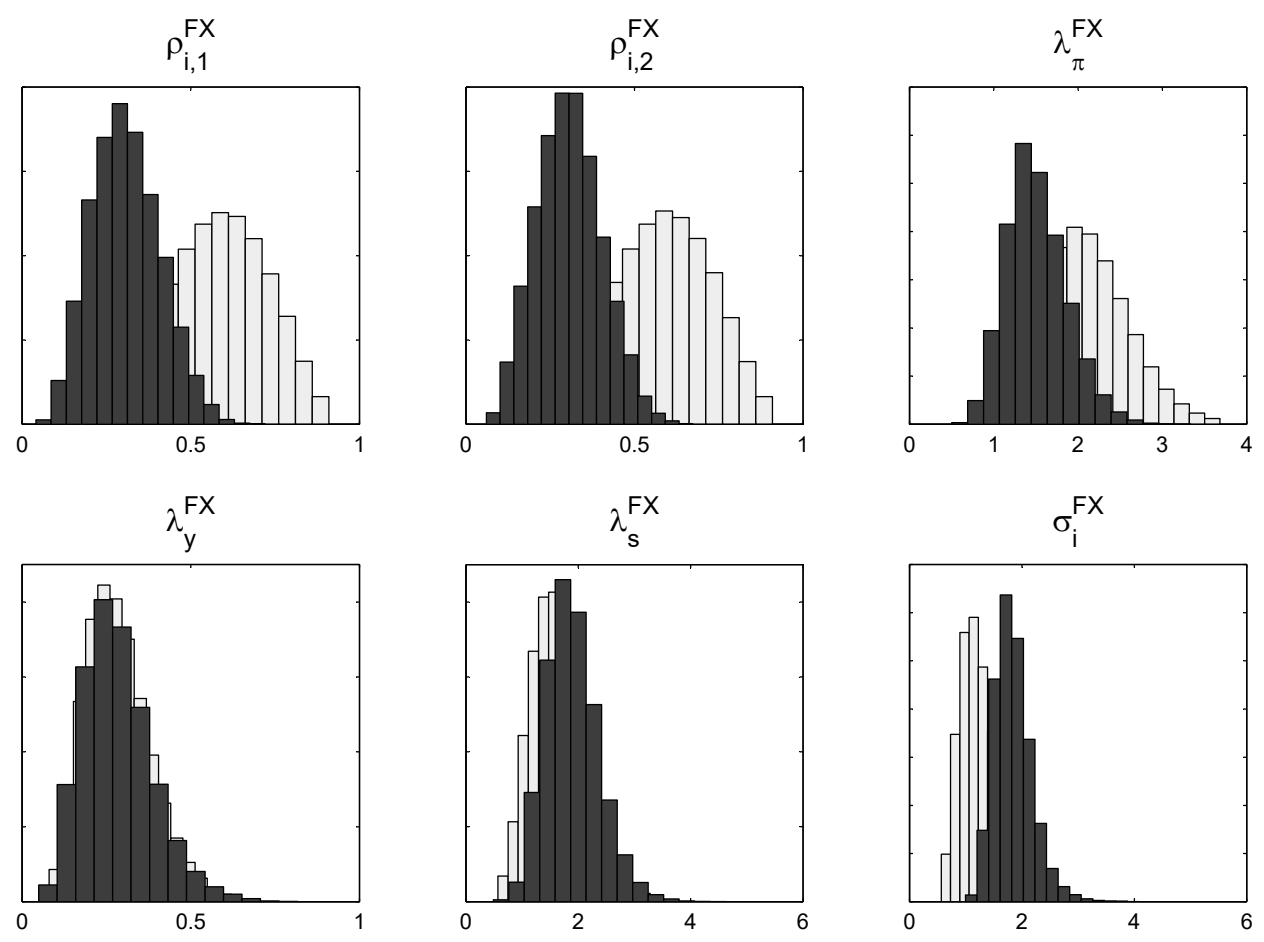

Figure 11: Marginal prior (light color) and posterior (dark color) distributions - Crawling peg regime.
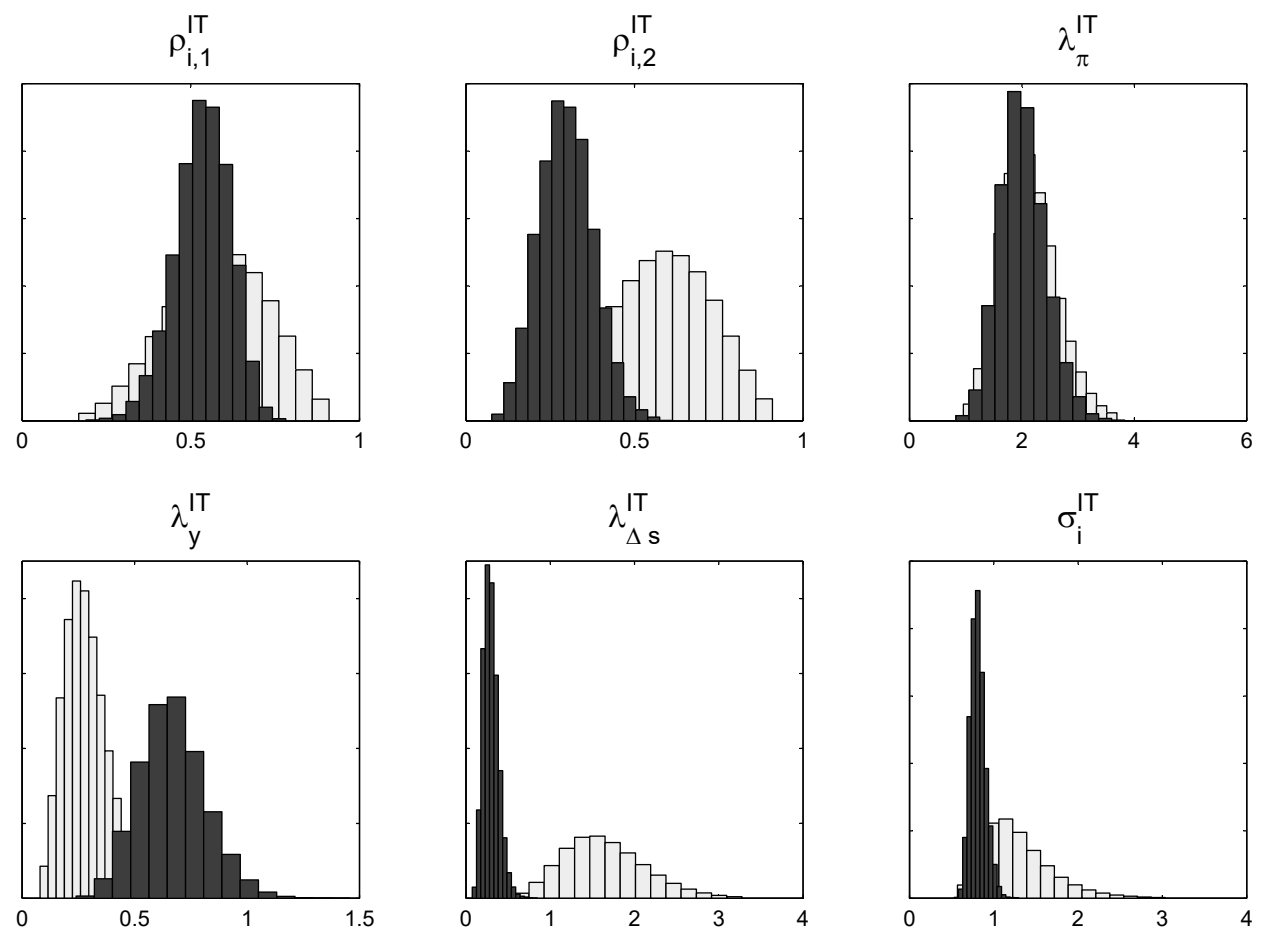

Figure 12: Marginal prior (light color) and posterior (dark color) distributions - Inflation targeting regime. 
Table 4: Variance decomposition - Crawling peg regime

\begin{tabular}{ccccccccc}
\hline \hline \multicolumn{1}{c}{$\epsilon_{i}$} & $\epsilon_{a}$ & $\epsilon_{\gamma}$ & $\epsilon_{\phi}$ & $\epsilon_{c p}$ & $\epsilon_{y^{*}}$ & $\epsilon_{\pi^{*}}$ & $\epsilon_{i^{*}}$ \\
\hline 1 quarter & & & & & & & \\
\hline$y$ & 3.45 & 3.83 & 72.54 & 13.33 & 2.43 & 3.47 & 0.19 & 0.76 \\
$\pi$ & 0.07 & 42.87 & 11.49 & 14.27 & 27.44 & 3.15 & 0.15 & 0.57 \\
$i$ & 56.29 & 1.81 & 1.31 & 33.29 & 1.22 & 0.81 & 0.17 & 5.11 \\
tot & 0.02 & 22.92 & 6.19 & 8.32 & 60.72 & 1.44 & 0.00 & 0.39 \\
$s$ & 32.65 & 4.15 & 3.33 & 50.33 & 3.91 & 0.16 & 0.01 & 5.47 \\
\hline 4 quarters & & & & & & & \\
\hline$y$ & 1.00 & 13.44 & 54.07 & 24.50 & 2.41 & 2.95 & 0.23 & 1.39 \\
$\pi$ & 0.07 & 45.11 & 8.99 & 16.36 & 22.71 & 5.92 & 0.30 & 0.55 \\
$i$ & 28.63 & 2.30 & 2.27 & 57.30 & 0.83 & 1.52 & 0.10 & 7.04 \\
tot & 0.01 & 43.82 & 5.28 & 17.67 & 27.71 & 4.80 & 0.01 & 0.71 \\
$s$ & 23.20 & 3.93 & 3.34 & 58.67 & 4.64 & 0.89 & 0.12 & 5.21 \\
\hline 20 quarters & & & & & & & & \\
\hline$y$ & 0.61 & 36.12 & 35.04 & 21.87 & 2.01 & 2.96 & 0.29 & 1.11 \\
$\pi$ & 0.09 & 40.15 & 12.03 & 20.56 & 19.08 & 6.96 & 0.37 & 0.75 \\
$i$ & 19.39 & 1.88 & 1.96 & 68.00 & 0.73 & 1.94 & 0.11 & 6.00 \\
tot & 0.16 & 43.02 & 6.83 & 12.37 & 11.20 & 26.03 & 0.02 & 0.37 \\
$s$ & 21.12 & 7.44 & 4.30 & 56.06 & 4.59 & 1.51 & 0.16 & 4.82 \\
\hline
\end{tabular}

Table 5: Variance decomposition - Inflation targeting regime

\begin{tabular}{|c|c|c|c|c|c|c|c|c|}
\hline & $\epsilon_{i}$ & $\epsilon_{a}$ & $\epsilon_{\gamma}$ & $\epsilon_{\phi}$ & $\epsilon_{c p}$ & $\epsilon_{y^{*}}$ & $\epsilon_{\pi^{*}}$ & $\epsilon_{i^{*}}$ \\
\hline \multicolumn{9}{|c|}{1 quarter } \\
\hline$y$ & 16.97 & 2.02 & 63.27 & 15.95 & 0.22 & 0.37 & 0.01 & 1.20 \\
\hline$\pi$ & 1.67 & 65.08 & 8.96 & 1.05 & 22.11 & 1.08 & 0.02 & 0.03 \\
\hline$i$ & 42.53 & 23.26 & 4.01 & 27.48 & 0.37 & 0.46 & 0.07 & 1.83 \\
\hline tot & 0.02 & 18.00 & 5.47 & 5.32 & 68.70 & 2.28 & 0.02 & 0.19 \\
\hline$s$ & 10.74 & 3.49 & 2.99 & 66.70 & 7.06 & 4.68 & 0.32 & 4.02 \\
\hline \multicolumn{9}{|c|}{4 quarters } \\
\hline$y$ & 14.04 & 19.83 & 58.00 & 6.93 & 0.32 & 0.37 & 0.02 & 0.48 \\
\hline$\pi$ & 1.63 & 73.90 & 6.35 & 1.15 & 15.33 & 1.60 & 0.03 & 0.03 \\
\hline$i$ & 22.53 & 40.06 & 17.58 & 16.74 & 1.77 & 0.30 & 0.04 & 1.00 \\
\hline tot & 0.07 & 33.72 & 5.06 & 17.50 & 33.92 & 9.03 & 0.08 & 0.61 \\
\hline$s$ & 9.21 & 7.71 & 2.51 & 62.16 & 7.88 & 6.99 & 0.58 & 2.97 \\
\hline \multicolumn{9}{|c|}{20 quarters } \\
\hline$y$ & 12.03 & 37.87 & 39.45 & 6.34 & 2.94 & 0.98 & 0.02 & 0.36 \\
\hline$\pi$ & 1.65 & 71.26 & 8.35 & 1.09 & 15.18 & 2.41 & 0.03 & 0.04 \\
\hline$i$ & 16.94 & 42.37 & 20.42 & 13.95 & 3.82 & 1.73 & 0.03 & 0.73 \\
\hline tot & 4.35 & 12.26 & 1.80 & 27.38 & 15.20 & 37.64 & 0.26 & 1.12 \\
\hline$s$ & 7.49 & 36.98 & 0.95 & 34.60 & 6.08 & 11.58 & 1.06 & 1.25 \\
\hline
\end{tabular}

